\title{
Evaluation of the Magnitude and Frequency of Floods in Urban Watersheds in Phoenix and Tucson, Arizona
}
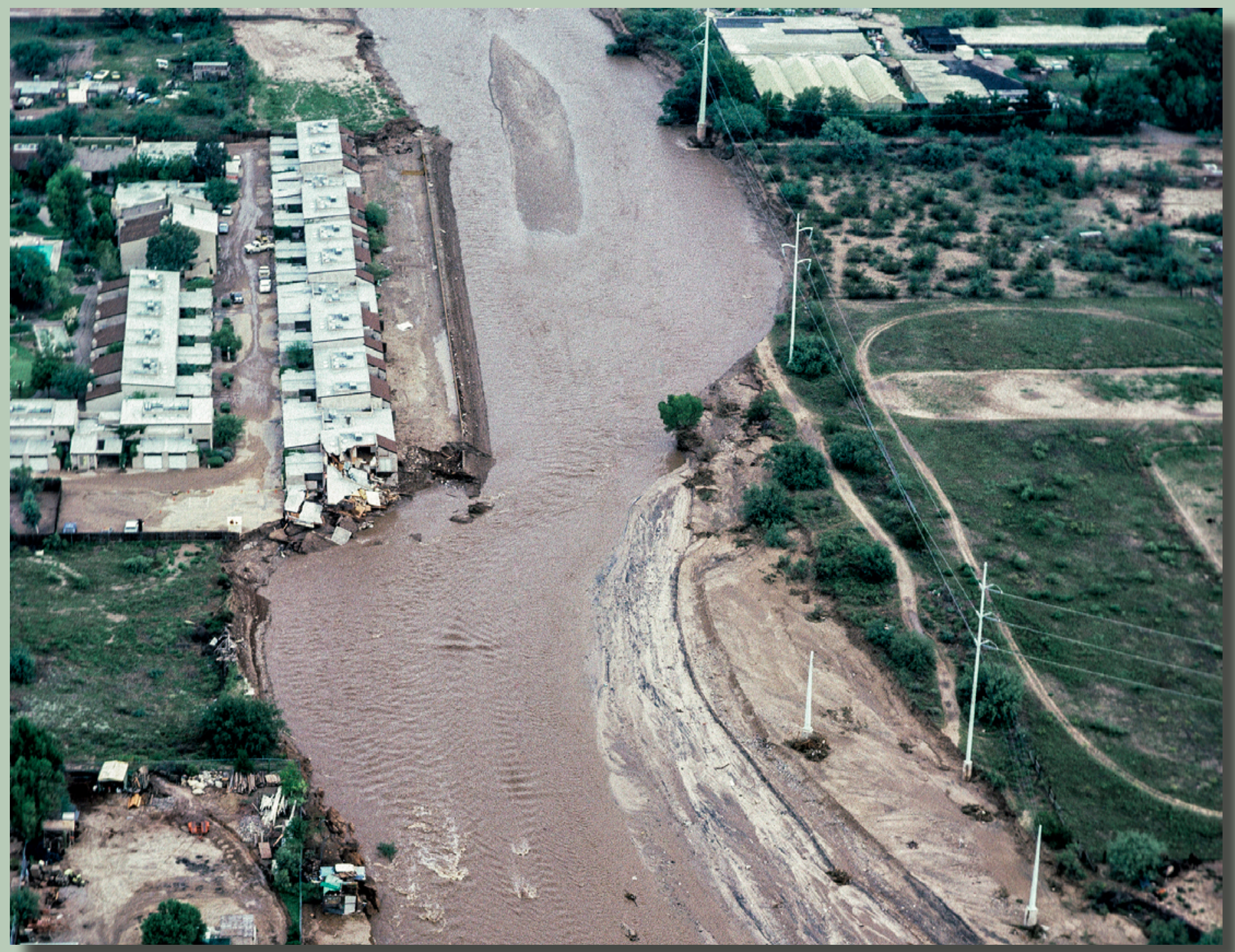

Scientific Investigations Report 2014-5121 
FRONT COVER

Photograph showing property damage caused by flooding of the Rillito River (looking downstream), Tucson, Arizona, following Tropical Storm Octave, October 4, 1983. (Photograph courtesy of kresanphotography.com; used with permission.) 


\section{Evaluation of the Magnitude and Frequency of Floods in Urban Watersheds in Phoenix and Tucson, Arizona}

By Jeffrey R. Kennedy and Nicholas V. Paretti

Prepared in cooperation with the Flood Control District of Maricopa County

Scientific Investigations Report 2014-5121 


\section{U.S. Department of the Interior SALLY JEWELL, Secretary}

\section{U.S. Geological Survey \\ Suzette M. Kimball, Acting Director}

U.S. Geological Survey, Reston, Virginia: 2014

For more information on the USGS - the Federal source for science about the Earth, its natural and living resources, natural hazards, and the environment—visit http://www.usgs.gov or call 1-888-ASK-USGS

For an overview of USGS information products, including maps, imagery, and publications, visit http://www.usgs.gov/pubprod

To order this and other USGS information products, visit http://store.usgs.gov

Suggested citation:

Kennedy, J.R., and Paretti, N.V., 2014, Evaluation of the magnitude and frequency of floods in urban watersheds in Phoenix and Tucson, Arizona: U.S. Geological Survey Scientific Investigations Report 2014-5121, 29 p.,

http://dx.doi.org/10.3133/sir20145121.

Any use of trade, product, or firm names is for descriptive purposes only and does not imply endorsement by the U.S. Government.

Although this report is in the public domain, permission must be secured from the individual copyright owners to reproduce any copyrighted material contained within this report.

ISSN 2328-0328 (online) 


\section{Contents}

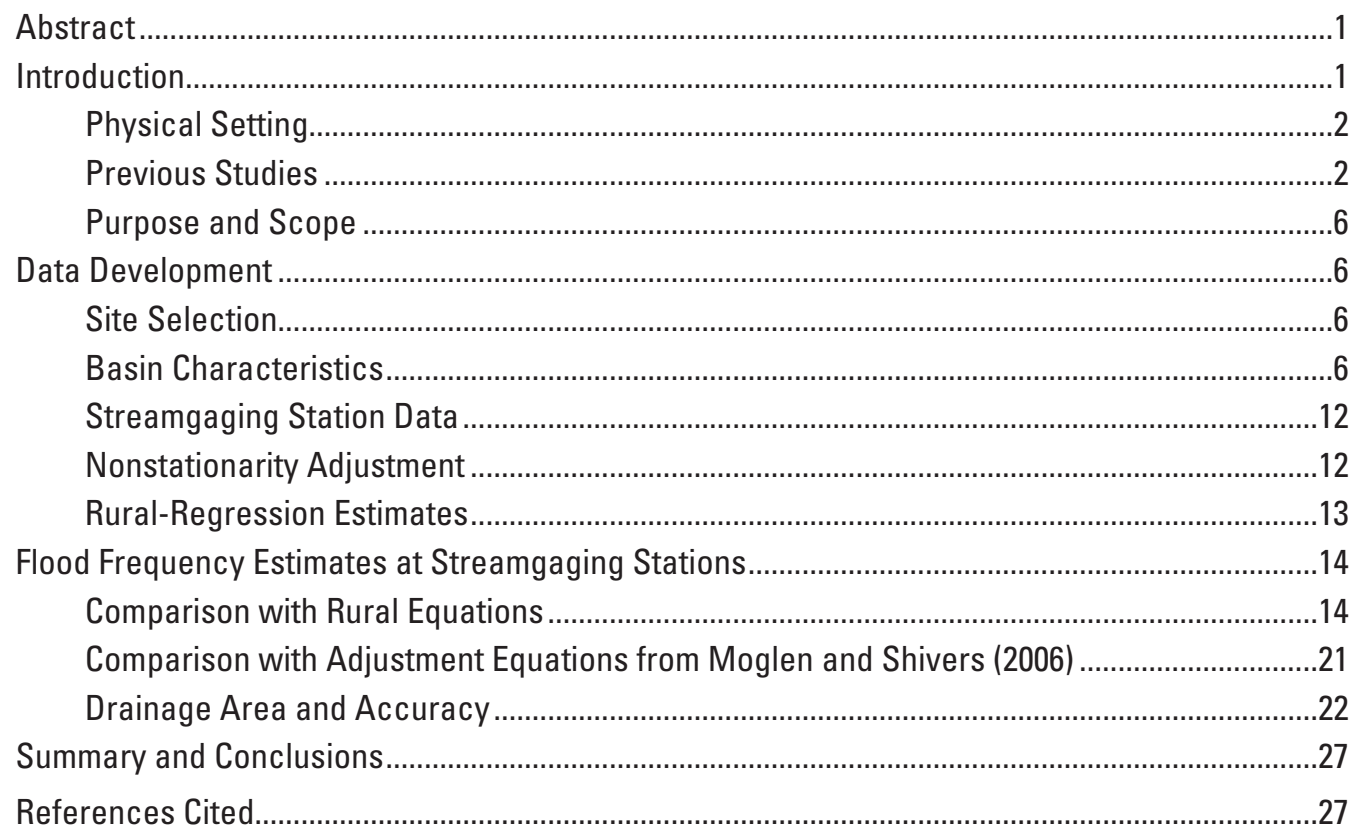

\section{Figures}

1. Overview map showing urban watersheds included in the study area of the Phoenix and Tucson, Arizona, metropolitan regions .............................................................................

2. Map showing urban watersheds in the Phoenix metropolitan area, Arizona ...........................4

3. Map showing urban watersheds in the Tucson metropolitan area, Arizona .............................5

4. Graph showing imperviousness and drainage areas for the urban streamgaging stations in the Phoenix and Tucson metropolitan areas, Arizona .................................................11

5. Graph showing locally weighted smoothing model relating population density from census data to impervious area for the urban streamgaging stations in the Phoenix and Tucson metropolitan areas, Arizona.....

6. Scatterplots showing the difference between predicted flood peaks at the urban streamgaging stations in the Phoenix and Tucson metropolitan areas, Arizona, included in the study and predicted flood peaks from rural-regression equations ........17

7. Scatterplots showing the difference between station and rural-regression flood-frequency estimates versus watershed imperviousness.

8. Scatterplots showing the difference between predicted flood peaks at urban streamgaging stations in the Phoenix and Tucson metropolitan areas, Arizona, and predicted flood peaks from rural-regression equations adjusted for urbanization ........23

9. Scatterplots showing the difference between station and rural-regression floodfrequency estimates adjusted for urbanization versus watershed imperviousness ......25

10. Graph showing annual peak flows for two streamgaging stations on Indian Bend Wash near Phoenix, Arizona. 


\section{Tables}

1. Streamgaging stations in urbanized watersheds in Phoenix and Tucson metropolitan areas,

Arizona

2. Flood frequency estimates at the urban streamgaging stations in the Phoenix and Tucson metropolitan areas, Arizona..

3. Coefficient of determination for the regression equations developed for the urban streamgaging stations in the Phoenix and Tucson metropolitan areas, Arizona, and pseudo- $R^{2}$ for the applicable regional rural-regression equations ................................21

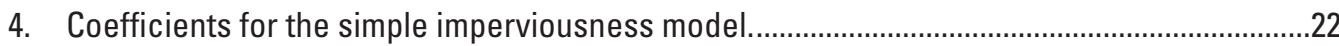




\section{Conversion Factors and Datums}

Inch/Pound to SI

\begin{tabular}{|c|c|c|}
\hline Multiply & By & To obtain \\
\hline \multicolumn{3}{|c|}{ Length } \\
\hline foot $(\mathrm{ft})$ & 0.3048 & meter $(\mathrm{m})$ \\
\hline mile (mi) & 1.609 & kilometer (km) \\
\hline meter $(\mathrm{m})$ & 3.281 & foot $(\mathrm{ft})$ \\
\hline \multicolumn{3}{|c|}{ Area } \\
\hline square mile $\left(\mathrm{mi}^{2}\right)$ & 2.590 & square kilometer $\left(\mathrm{km}^{2}\right)$ \\
\hline square kilometer $\left(\mathrm{km}^{2}\right)$ & 0.3861 & square mile $\left(\mathrm{mi}^{2}\right)$ \\
\hline \multicolumn{3}{|c|}{ Flow rate } \\
\hline cubic foot per second $\left(\mathrm{ft}^{3} / \mathrm{s}\right)$ & 0.02832 & cubic meter per second $\left(\mathrm{m}^{3} / \mathrm{s}\right)$ \\
\hline
\end{tabular}

\section{Datums}

Vertical coordinate information is referenced to the North American Vertical Datum of 1988

(NAVD 88).

Horizontal coordinate information is referenced to the North American Datum of 1983 (NAD 83).

Elevation, as used in this report, refers to distance above the vertical datum. 
This page intentionally left blank. 


\title{
Evaluation of the Magnitude and Frequency of Floods in Urban Watersheds in Phoenix and Tucson, Arizona
}

\author{
By Jeffrey R. Kennedy and Nicholas V. Paretti
}

\begin{abstract}
Flooding in urban areas routinely causes severe damage to property and often results in loss of life. To investigate the effect of urbanization on the magnitude and frequency of flood peaks, a flood frequency analysis was carried out using data from urbanized streamgaging stations in Phoenix and Tucson, Arizona. Flood peaks at each station were predicted using the log-Pearson Type III distribution, fitted using the expected moments algorithm and the multiple Grubbs-Beck low outlier test. The station estimates were then compared to flood peaks estimated by rural-regression equations for Arizona, and to flood peaks adjusted for urbanization using a previously developed procedure for adjusting U.S. Geological Survey rural regression peak discharges in an urban setting. Only smaller, more common flood peaks at the 50-, 20-, 10-, and 4-percent annual exceedance probabilities (AEPs) demonstrate any increase in magnitude as a result of urbanization; the 1-, 0.5-, and 0.2-percent AEP flood estimates are predicted without bias by the rural-regression equations. Percent imperviousness was determined not to account for the difference in estimated flood peaks between stations, either when adjusting the ruralregression equations or when deriving urban-regression equations to predict flood peaks directly from basin characteristics. Comparison with urban adjustment equations indicates that flood peaks are systematically overestimated if the rural-regression-estimated flood peaks are adjusted upward to account for urbanization. At nearly every streamgaging station in the analysis, adjusted rural-regression estimates were greater than the estimates derived using station data. One likely reason for the lack of increase in flood peaks with urbanization is the presence of significant stormwater retention and detention structures within the watershed used in the study.
\end{abstract}

\section{Introduction}

Flood-frequency estimates in urban areas are important for mitigating flood damage and planning for the adequate conveyance of stormwater runoff. Generally, predicted flood peaks are larger in urban watersheds than rural watersheds, which has led to the development of flood-frequency regression equations that are specific to urban areas and account for urbanization factors such as imperviousness and channel development (Sauer and others, 1983; Moglen and Shivers, 2006). Because urbanization is accompanied by an increase in impervious areas, less rainfall infiltrates, potentially increasing flood volume. Furthermore, runoff is routed to the watershed outlet more quickly by impervious streets, channels, and subsurface storm drains, potentially decreasing the time of concentration and increasing the magnitude of flood peaks. The increase in runoff with urbanization is largest in relatively small watersheds, where convective storms are the primary source of annual flood peaks (Kennedy and others, 2013), and for more common, higher annual exceedance probability (AEP) floods. The magnitudes of flood peaks caused by larger, less-frequent floods are determined primarily by storm characteristics and less by watershed characteristics, and therefore are less influenced by urbanization (Moglen and Shivers, 2006).

Historically, large floods in urban areas in the Southwest have motivated the construction of extensive floodmitigation structures and changes in development codes. In 1972, flooding of the Indian Bend Wash in Scottsdale, Arizona, caused widespread property damage that prompted construction of the Indian Bend Wash Greenbelt, a linear series of parks, turf areas, and golf courses. The greenbelt was a significant departure from more traditional concretelined storm drains, and served the dual purpose of conveying flood waters and providing open space for recreation (City of Scottsdale, 1985). Many floodwater detention facilities that serve as parks or open space have subsequently been constructed. Other major flood control projects in the Phoenix area, constructed and (or) maintained primarily by the Flood Control District of Maricopa County, include the Arizona Canal Diversion Channel, East Maricopa Floodway, and Cave Buttes and Adobe Dams. In Tucson, extensive flooding caused by rainfall from tropical storm Octave in 1983 resulted in over $\$ 10$ million in property damage (Saarinen and others, 1984). The city responded by installing extensive bank protection along the Rillito and Santa Cruz Rivers and restricting development in floodplains.

The frequency of flood peaks is commonly expressed either in terms of AEP (between 0 and 1.0) or as a recurrence interval (in years). AEP refers to the probability of a flood peak of a given magnitude in a particular year; it is the reciprocal of the recurrence interval. For example, the 1-percent AEP flood is equivalent to the 100 -year recurrence interval flood. AEP is used instead of return interval to indicate that annual flood peaks are independent, and the occurrence of a large flood in one year 
does not preclude the occurrence of a similarly large flood in the same or any subsequent year.

Peak flow frequency estimates for rural watersheds (Paretti and others, 2014b) are available online in the StreamStats web application at http://streamstatsags.cr.usgs. gov/az_ss. StreamStats is a national U.S. Geological Survey (USGS) map-based web application that provides easy access to published flood frequency and basin characteristic statistics for user-selected States. The interactive web application allows the user to select a point on a stream channel (gaged or ungaged), delineate a watershed boundary, and retrieve flood-frequency estimates derived from the current regional regression equations and geographic information system (GIS) data within the basin selected. StreamStats provides consistent statistics, minimizes user error, and reduces the need for large datasets and costly standalone GIS software.

\section{Physical Setting}

Stormwater runoff in the Phoenix and Tucson metropolitan areas (fig. 1) is generally routed toward large, natural waterways that originate outside the urban regions. In Phoenix, the major waterways are the Agua Fria River, with tributaries New River, Skunk Creek and Cave Creek; and the Salt River, with Indian Bend Wash as the major tributary within the urban area (fig. 2). In addition to these natural channels, many additional flood-control structures built or maintained by the Flood Control District of Maricopa County (FCDMC) and the Arizona Department of Transportation are used for storm drainage - for example, the Arizona Canal Diversion Channel and East Maricopa Floodway. In the Tucson area, the Santa Cruz and Rillito Rivers are the major natural waterways that convey stormwater (fig. 3). Major flood-control channels and canals are less common than in the Phoenix area, and more stormwater is conveyed via surface streets. The study focuses on watersheds that are heavily influenced by urbanization, and therefore excludes streamgaging stations directly on the largest rivers in the urban areas, where large flood events are generally caused by non-urban runoff and are less sensitive to the amount of impervious area in the watershed.

The urban watersheds in this study are located in the Basin and Range Province in the Southwestern United States. Precipitation events responsible for flooding in this region can be broadly grouped into convective, frontal, and tropical storms. Convective storms related to the summertime North American Monsoon can be unpredictable and intense, but they are usually limited in spatial extent (Adams and Comrie, 1997). Convective storms routinely cause the annual peak floods in smaller watersheds, and, together with accompanying winds, can cause extensive property damage. In larger watersheds, the typically wider spatial extent of winter frontal storms are responsible for relatively more annual peak flows, although convective storms still can be a common source of annual peaks. Many floods of record occur when widespread winter frontal storms saturate soil to capacity so that short periods of localized intense rainfall can cause rapid runoffalthough less frequent, extreme flooding can also occur during dissipating tropical storms. For many streamgaging stations in this study, the flood of record occurred with peak flows caused by tropical storm Octave in 1983 (Saarinen and others, 1984).

\section{Previous Studies}

A widely used method for estimating urban flood peaks is to adjust the estimated peak flow for a rural watershed by a factor determined using regression equations that relate the increase in runoff to the amount of urbanization. Two sets of regression equations are involved: first, rural-regression equations relate the estimated peak flow in an equivalent rural watershed to basin characteristics, such as drainage area; second, adjustment-regression equations relate the peak flow in the equivalent rural watershed to urbanization characteristics, such as percent imperviousness or population density. Sauer and others (1983) developed adjustmentregression equations using drainage area, channel slope, rainfall intensity, basin storage, impervious area, and basin development factor (BDF) as explanatory variables. BDF is a semi-quantitative measure that includes the spatial distribution of channel improvements, channel linings, storm sewers, and curb-and-gutter streets. A second set of adjustmentregression equations, using only drainage area and BDF, were also presented in Sauer and others (1983). Out of 199 sites in the nationwide analysis, four Tucson streamgaging stations (U.S. Geological Survey station numbers 09483000 , 09483010, 09483042, 09485550) were used. In an update to the Sauer and others (1983) report, motivated in part by the difficulty in determining BDF, Moglen and Shivers (2006) developed adjustment-regression equations that used percent imperviousness (from the National Land Cover Dataset) and population density (from U.S. Census Bureau data) as explanatory variables. No Arizona sites were used in that study.

In Tucson, Eychaner (1984) used the regression equations of Sauer and others (1983) based on two explanatory variables, drainage area and BDF, and determined they were unbiased with respect to all Tucson streamgaging stations. Gaged basins had BDFs ranging from 3 to 9 (mean 5.6), drainage areas from 0.95 to 8.2 square miles, slopes from 0.6 to 1.1 percent, and elevations from 2,300 to 2,700 feet. This relatively small range of basin characteristics limited evaluation of the effectiveness of the Sauer and others (1983) equations for urban sites outside this range. For the streamgaging station Santa Cruz River at Tucson, Webb and Betancourt (1992) determined that floods increased in magnitude after 1960; this increase was also present at all upstream stations, which were unaffected by urbanization and no modifications to the flood frequency analysis were made to account for urbanization.

Instead of adjusting the flood peaks predicted for a rural watershed, Southard (2010) used Bulletin 17B methods 


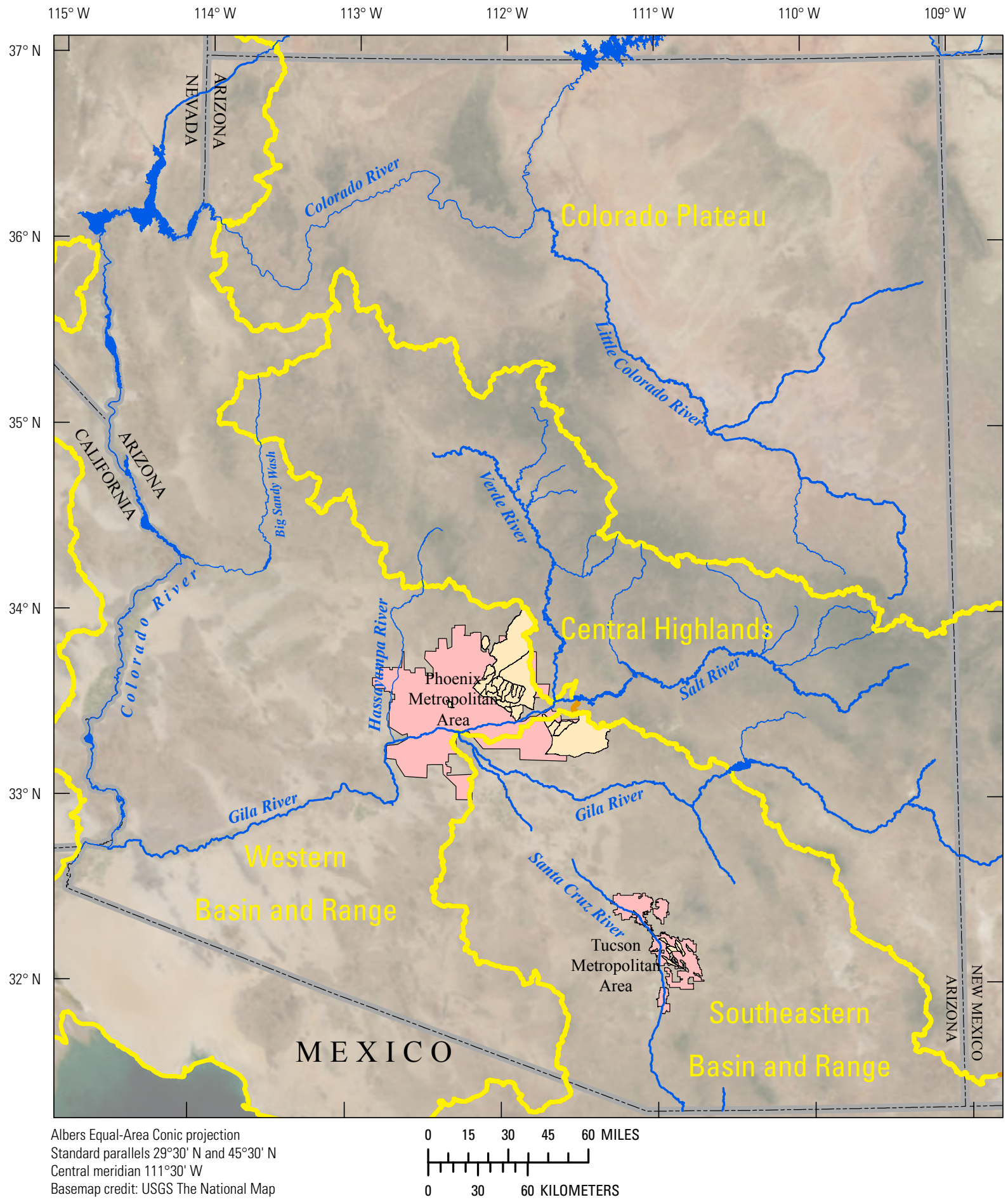

\section{EXPLANATION}

Regions defined in Paretti and others (2014b)

\section{Urban watershed}

Figure 1. Overview map showing urban watersheds included in the study area of the Phoenix and Tucson, Arizona, metropolitan regions (Paretti and others, 2014b). (Note that Western and Southeastern Basin and Range, as well as Central Highlands, are informal names, only capitalized in this report for clarity.) 


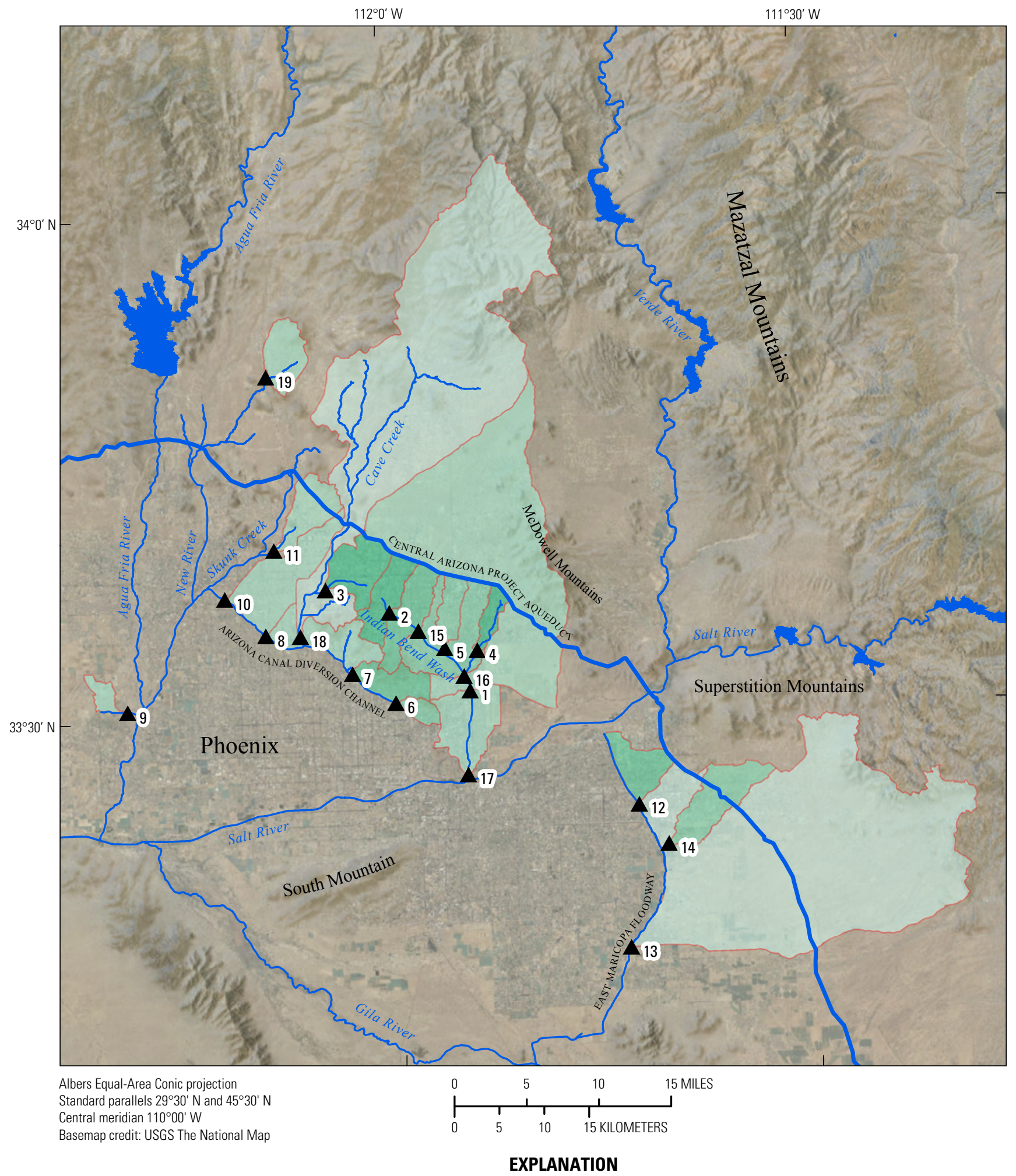

A Streamgaging station and map index

Urban watersheds-mean imperviousness, in percent

$\begin{array}{llllll}0 & 10 & 20 & 30 & 40 & 50\end{array}$

Figure 2. Map showing urban watersheds in the Phoenix metropolitan area, Arizona. Map IDs are defined in table 1. 


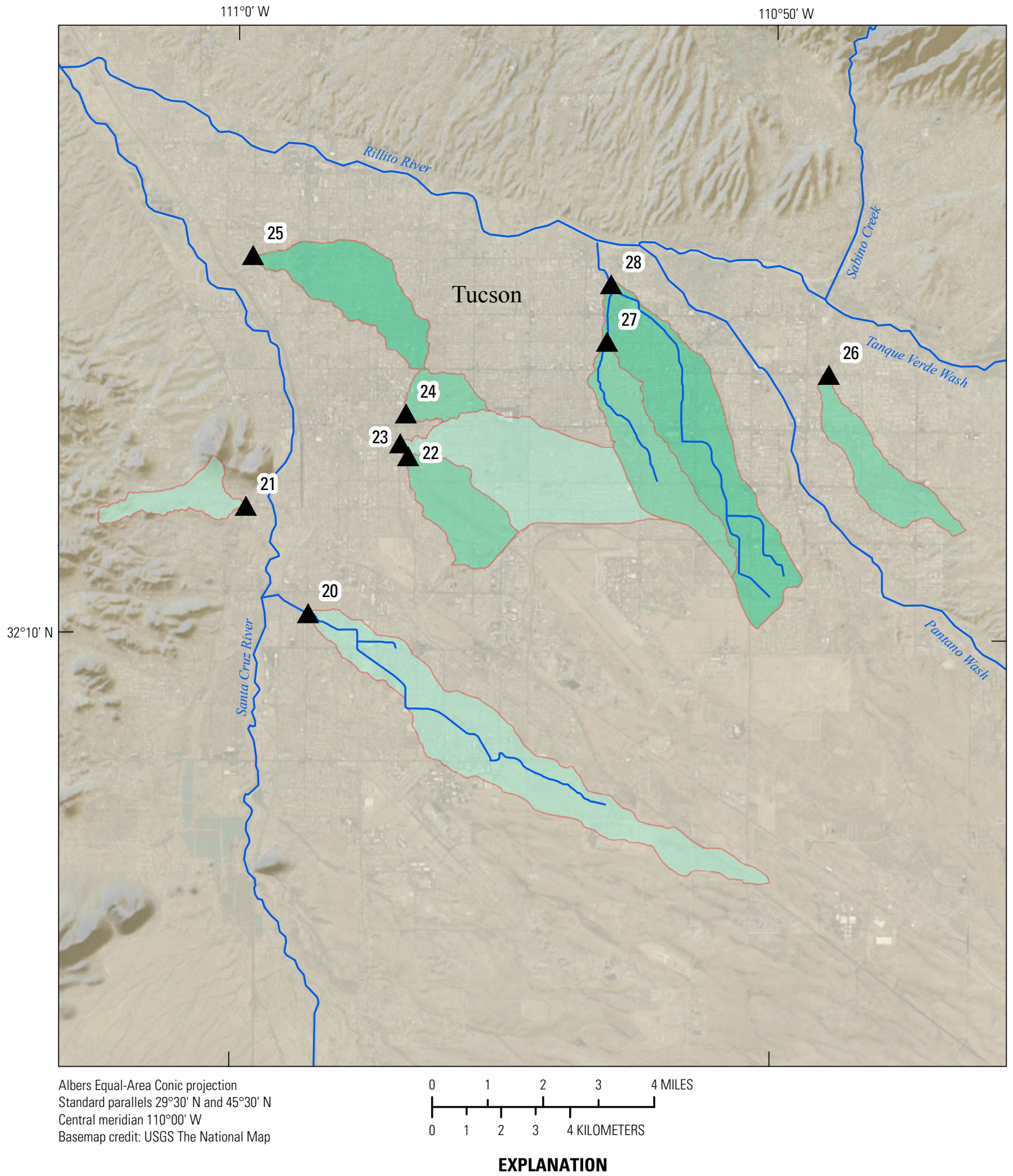

$\Delta$ Streamgaging station and map index

Urban watersheds - mean imperviousness, in percent

10

20

Figure 3. Map showing urban watersheds in the Tucson metropolitan area, Arizona. Map IDs are defined in table 1. 
(Interagency Advisory Committee on Water Data, 1982) to directly predict flood peaks from urban watersheds and develop regional regression equations using weighted least squares regression. The analysis used data from 35 streamgaging stations in Missouri and surrounding States. Percent imperviousness and drainage area were variables in the regression. Predicted flood peaks were similarly sensitive to both parameters, and sensitivity to imperviousness area decreased for smaller AEPs. A similar study in Georgia (Gotvald and Knaak, 2011) presented regression equations for urban watersheds using drainage area, and, depending on the hydrologic region, either percent imperviousness or percent developed land, both from the National Land Cover Database (NLCD; Homer and others, 2007). The study incorporated a large number of non-urbanized streamgages with the intent that the urban regression equations would converge to the rural regression equations when percent imperviousness or percent developed land approached zero.

An investigation to update regional flood frequency statistics in California evaluated flood peaks at urban streamgaging stations (Gotvald and others, 2012). Eight urban stations were identified with greater than 10 percent impervious area and with records representing homogeneous periods of urbanization (that is, when percent imperviousness was not changing). Because of the small sample size regional regression equations were not developed, but the predicted flood peaks at various AEPs using the urban streamgaging station data were compared to the corresponding flood peaks predicted from the regional regression equations. At nearly every streamgage and every AEP, measured flood peaks at the urban streamgaging stations were larger than peaks predicted from the rural regression equations.

\section{Purpose and Scope}

This report presents peak flow estimates for 50-, 20-, 10-, 4-, 2-, 1-, and 0.5-percent AEPs for 33 urbanized watersheds in Phoenix and Tucson, Arizona. Peak flow estimates are compared to estimates derived from rural regression equations (Paretti and others, 2014b), and to the rural-regression estimates adjusted to account for urbanization using the equations in Moglen and Shivers (2006).

\section{Data Development}

\section{Site Selection}

To identify streamgaging stations potentially influenced by urbanization, an initial list of 54 streamgaging stations was compiled for the metropolitan areas of Phoenix and Tucson, Arizona. Additional watersheds in Prescott and Flagstaff, Arizona, were investigated, but were not sufficiently urbanized for purposes of this study. Twenty stations in the Las Vegas, Nevada, area were also considered, but were excluded because the streamgaging record was pre-urbanization, there was too little impervious area, or there were major modifications to pre-urbanization watershed boundaries during the period of record. Stations operated by the USGS, FCDMC, and Pima County (Arizona) Regional Flood Control District (PCRFCD) were considered. Imperviousness data from the 2001 NLCD (Yang and others, 2003) were used to evaluate the degree of urbanization within each watershed. Ten sites, although located in or near urbanized areas, were removed from the analysis because the impervious surfaces comprised less than 5 percent of the watershed area (table 1). Five percent imperviousness is often considered the minimum threshold for urbanization to influence flood frequency (Brabec and others, 2002). Two additional watersheds with greater than 5 percent imperviousness were removed because the watershed areas were large (greater than 500 square miles) and imperviousness was concentrated in a small area. Five watersheds were removed because the drainage area was not well defined, primarily because subsurface storm sewers and other modifications to watershed boundaries obscure the natural topographic boundaries. Drainage area is the primary basin characteristic used to predict peak flows in Arizona (Paretti and others, 2014b), and an accurate comparison of urban and rural flood frequency estimates depends on accurate watershed area determination. The peak flow record at each site was evaluated relative to the period of urbanization, based on U.S. Census Bureau (2010) population density estimates and visual inspection of historical aerial photographs; seven sites were removed because data were collected pre-urbanization (three of these sites were co-located with streamgaging stations that collected urban-affected peak flows under an alternate station identification shown in table 1). Finally, two stations were removed because they were located very near other stations during the same period of record and were determined to be redundant. After removal of the unsuitable stations, 28 stations with well-defined watershed areas and imperviousness greater than 5 percent were used in the analysis (table 1).

The streamgages used for this study generally are in small (20 square miles or less) or large (100 square miles or more) watersheds (fig. 4). Imperviousness in the small group ranges between 12 and 50 percent, and many of the watersheds can be considered completely urbanized. The large watersheds are primarily those that originate outside of the urban areas, with the exception of Indian Bend Wash in Scottsdale. Imperviousness in these watersheds ranges from 8 to 18 percent.

\section{Basin Characteristics}

Urbanization modifies natural runoff pathways and watershed boundaries to be modified, and as a result, 


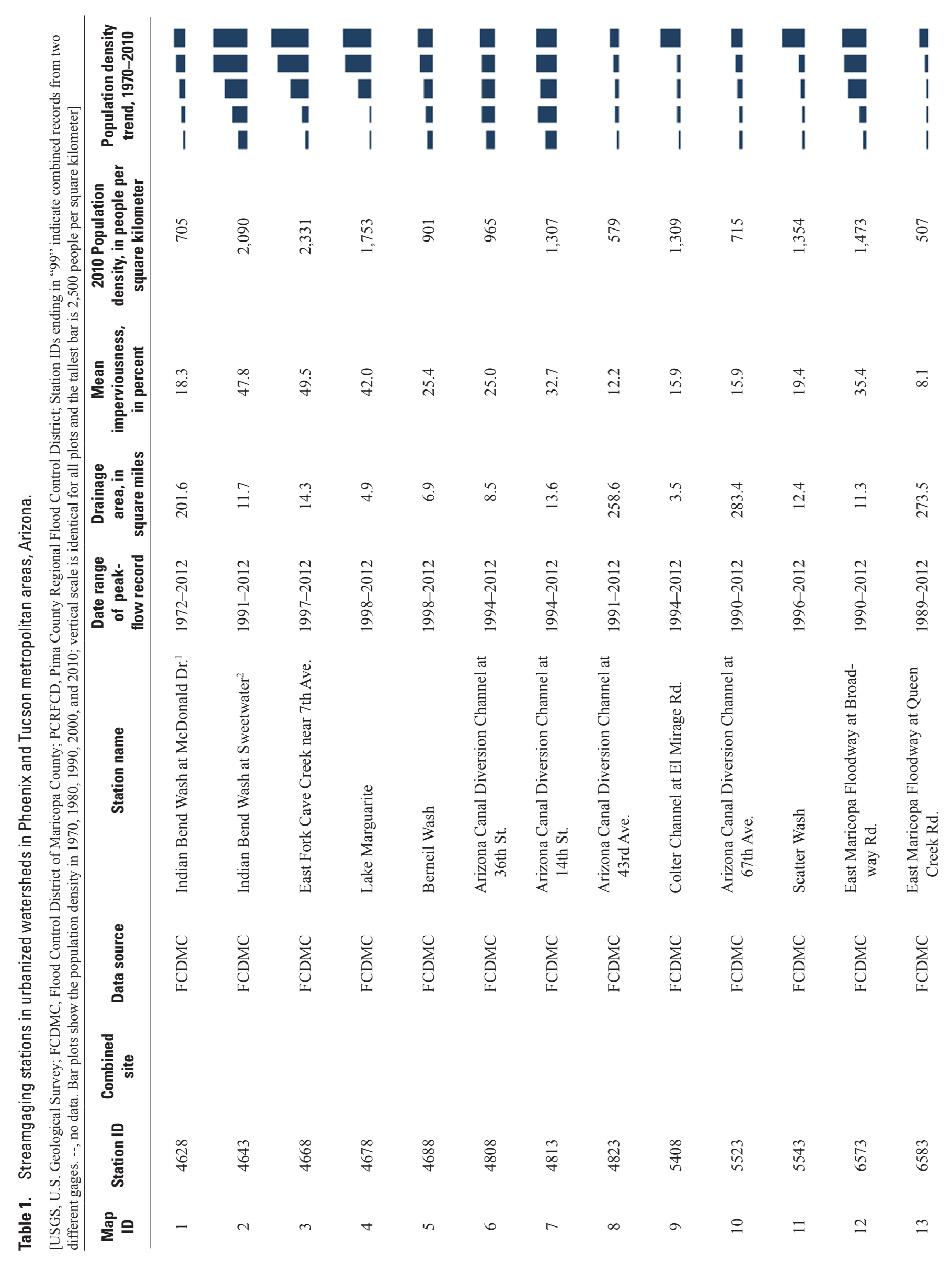



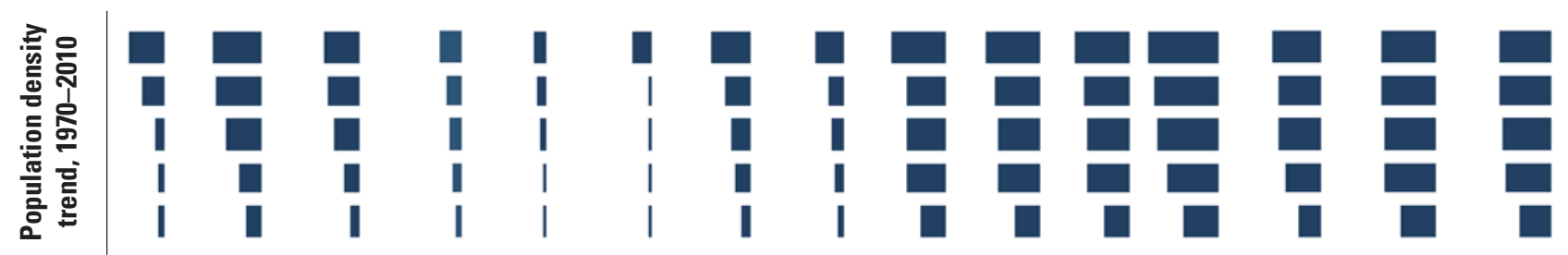

흠

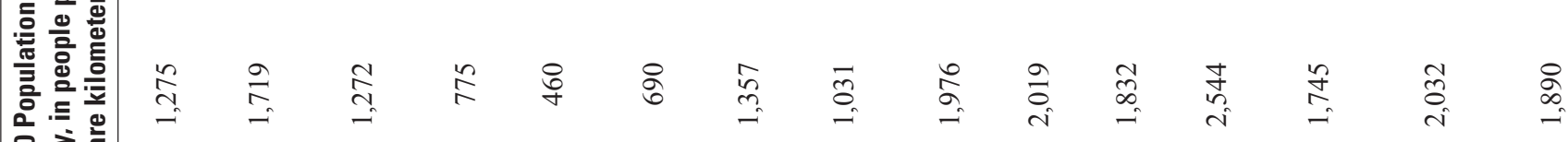
高管言

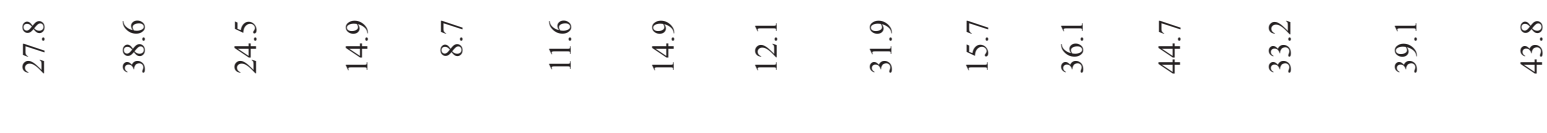

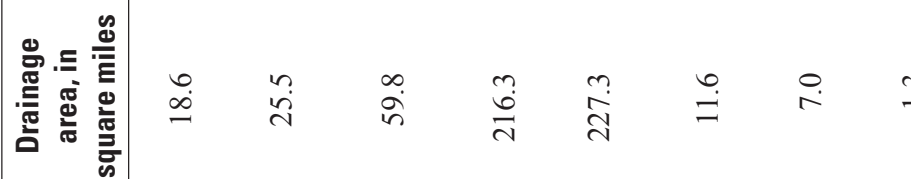

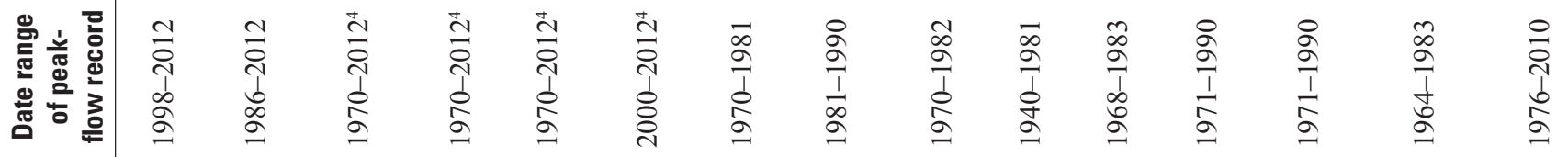
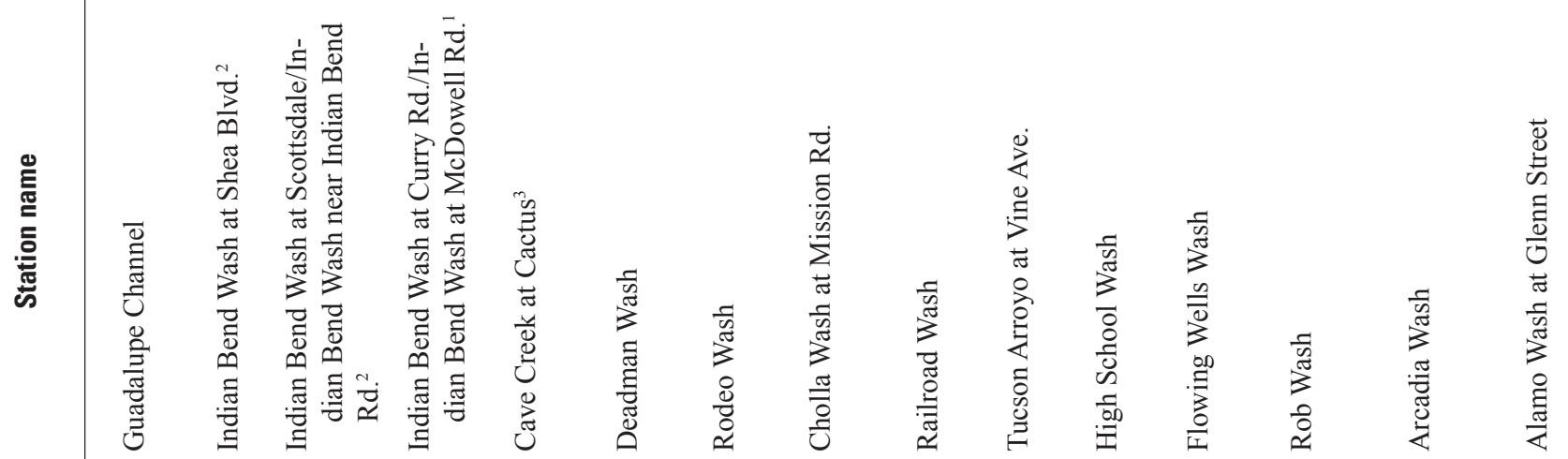

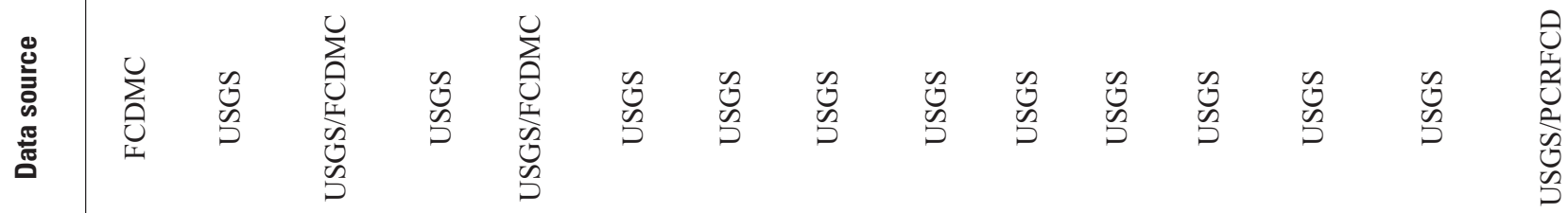

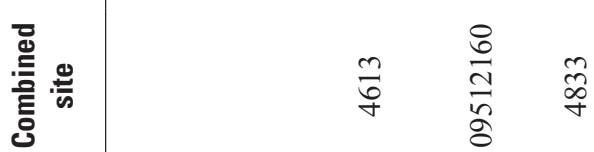

$\stackrel{?}{\stackrel{2}{2}}$

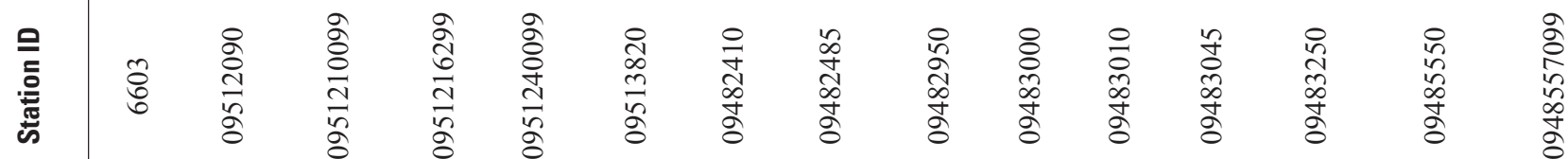

를으

$\pm \quad n$

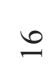

$=\quad \infty$

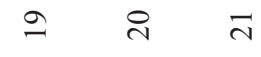

ก

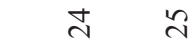

$\stackrel{\Lambda}{\wedge}$

$\stackrel{\infty}{\sim}$ 


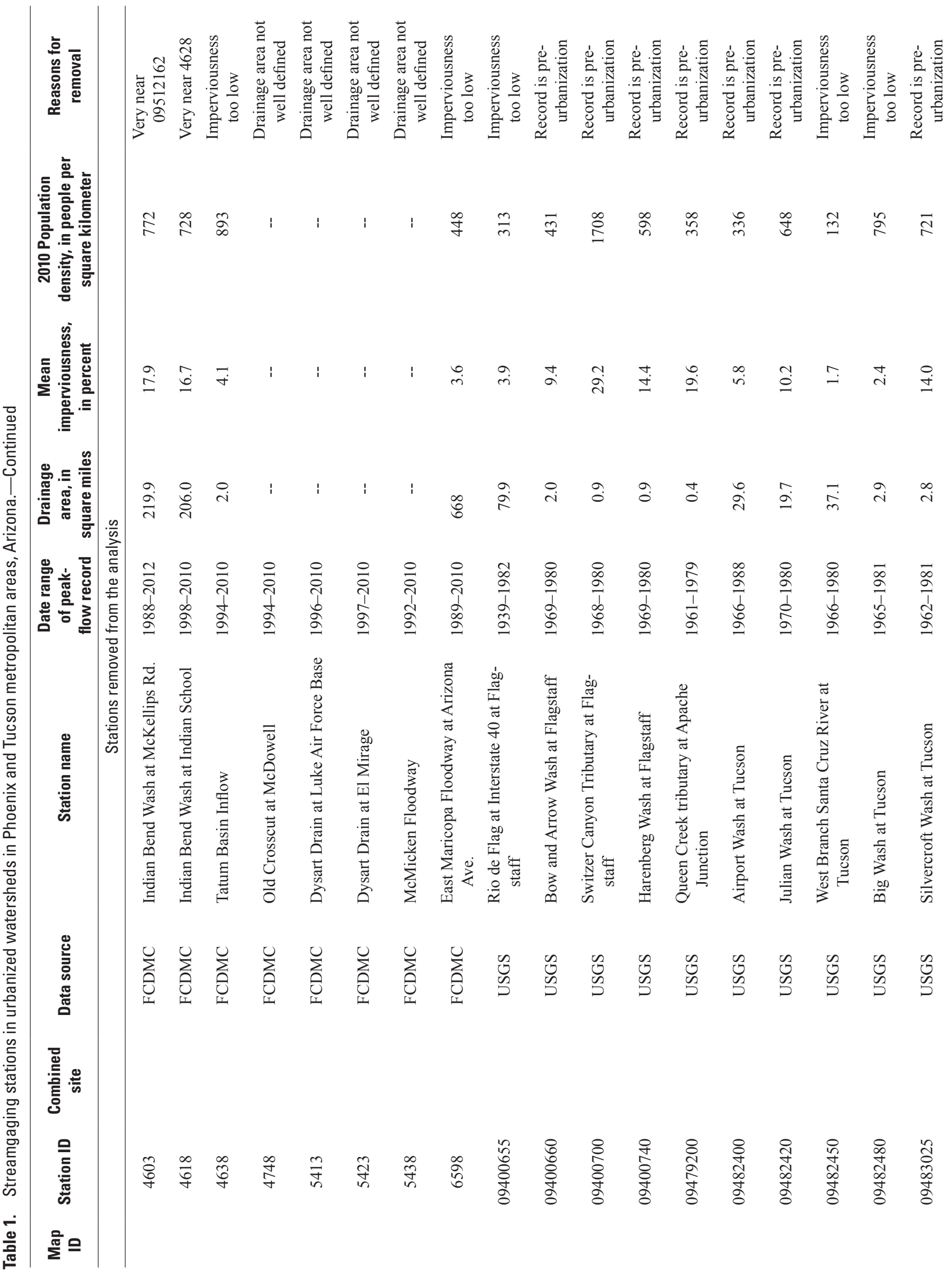




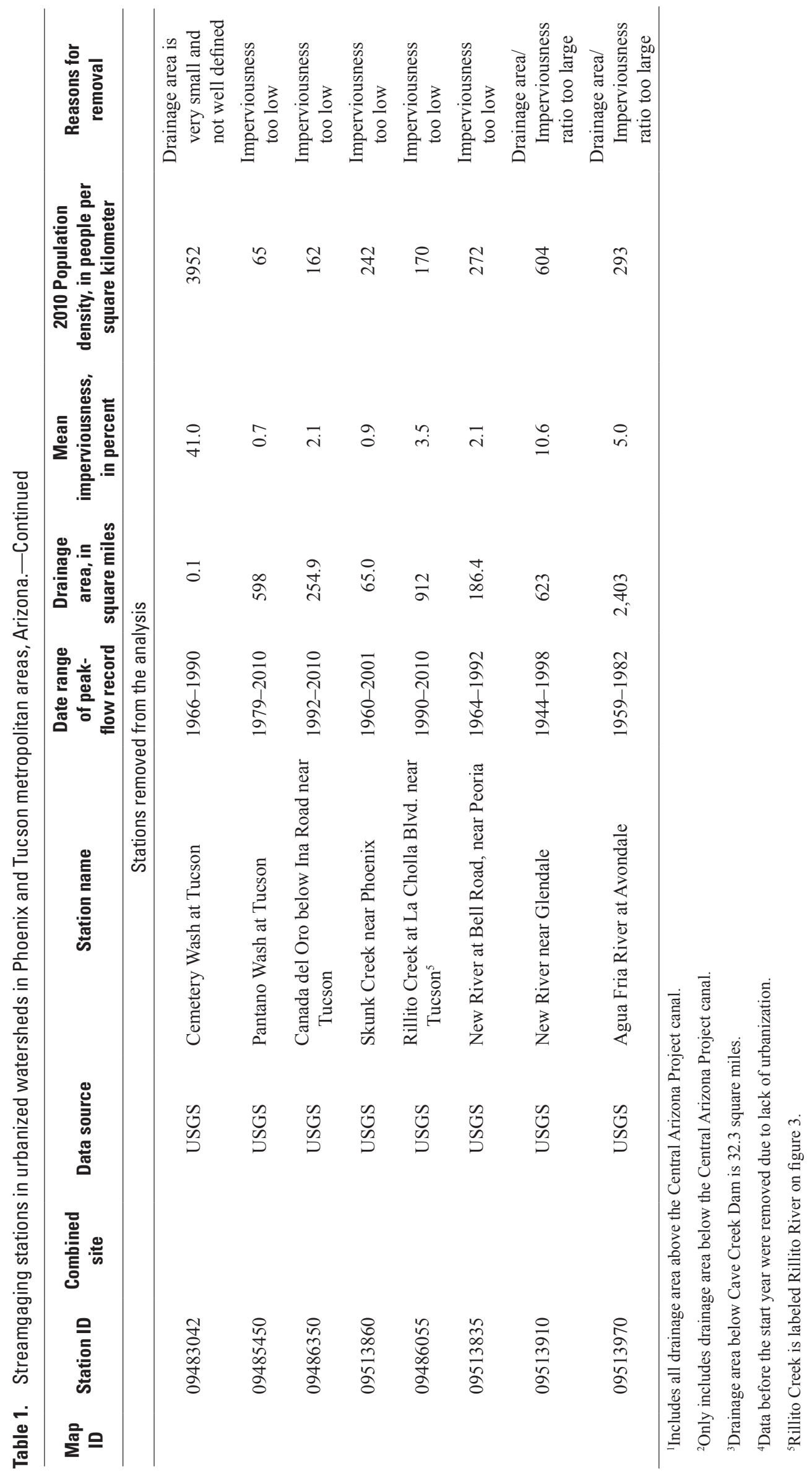




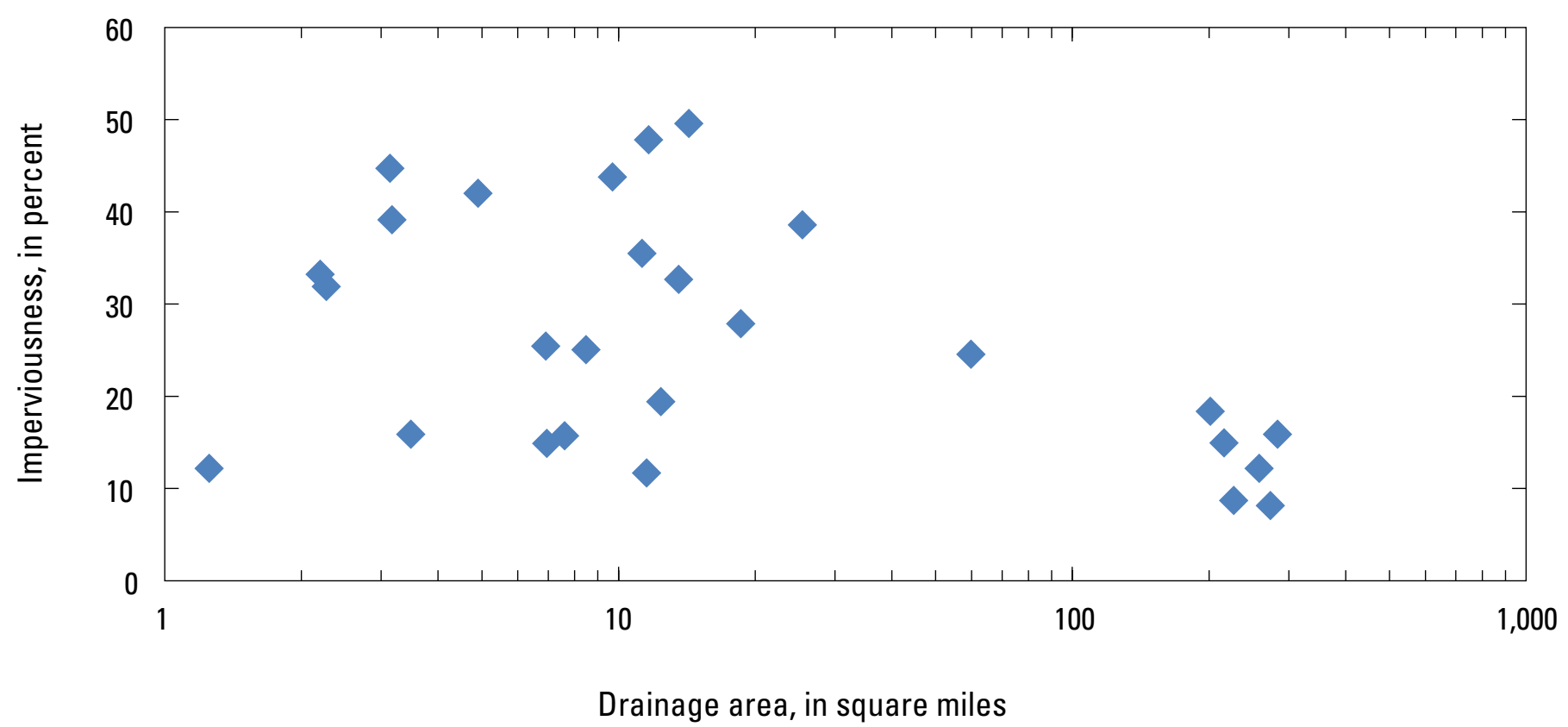

Figure 4. Graph showing imperviousness and drainage areas for the urban streamgaging stations in the Phoenix and Tucson metropolitan areas, Arizona, included in the study.

watershed divides and contributing areas can be difficult to determine from topographic data. Storm runoff also may be routed to detention basins (designed to slow stormwater runoff), retention basins (designed to capture all stormwater runoff), and dry wells (large-diameter boreholes which quickly transmit water to the unsaturated zone), each of which reduces the effective contributing watershed area of a particular streamgaging station. Dry wells are particularly common in the Phoenix area: as of July 2012, the Arizona Department of Environmental Quality database lists 4,400 dry wells in Phoenix, 1,660 in Chandler, and 1,049 in Mesa; just 130 dry wells are listed for the City of Tucson. Although these watershed modifications reduce the amount of water entering stream channels, urbanization is also accompanied by an increase in impervious area, which increases runoff. Ultimately, land-use policies in Phoenix, Tucson, and elsewhere seek to balance the increase in impervious area with mitigation measures, so that the peak runoff rate from urban areas is not greater than from rural areas. As it is not feasible for this study to accurately quantify the amount of stormwater storage within each watershed, the flood-frequency estimates presented incorporate the effect of flood-mitigation measures. Therefore, the analysis provides one method to evaluate their effectiveness.

The StreamStats GIS viewer uses topographic data, the USGS National Hydrographic Dataset (NHD), and the NHD Watershed Boundary Dataset to delineate watershed boundaries. Several modifications were made to NHD boundaries in the Phoenix area using data from FCDMC, Arizona Department of Transportation drainage maps, and stormwater management plans prepared by cities in the Phoenix metropolitan area:
- Since 1975, the Central Arizona Project Aqueduct in north Phoenix and Scottsdale has been a barrier to stormwater runoff reaching Indian Bend Wash from the north and northeast (Pope and others, 1998). Some runoff is routed to the southeast before it enters the wash above the Arizona Canal and station Indian Bend Wash near Indian Bend Road (FCDMC site 4613, map ID 16). There is substantial retention storage behind the Central Arizona Project Aqueduct, and flood peaks originating in this upland area are largely attenuated before reaching Indian Bend Wash. Watersheds that receive runoff from the north and east-East Fork Cave Creek near 7th Ave. (FCDMC site 4668, map ID 3), Indian Bend Wash at Sweetwater (FCDMC site 4643, map ID 2), Indian Bend Wash at Shea Blvd. (09512090, map ID 15), Berneil Wash (FCDMC site 4688, map ID 5), and Lake Marguarite (FCDMC site 4678, map ID 4) — are truncated at the Central Arizona Project Aqueduct. However, there are small conveyance structures that allow runoff from large storms to cross over the canal. For these storms, the watershed contributing area may vary depending on whether detention storage behind the canal is inundated and floodwater crosses over the canal.

- Adobe Mountain Dam in northwest Phoenix routes water from Skunk Creek to station Adobe Dam Outlet (FCDMC site 5538; not included in table 1); this was not reflected in the NHD.

- A diversion channel along the north side of Luke Air Force Base in west Phoenix, the Dysart Drain, reduces the size of the watershed at station Colter Channel at El 
Mirage Road (FCDMC site 5408; map ID 9) from what was indicated by the NHD and topography. Runoff that enters Dysart Drain from the north is routed to the Agua Fria River and bypasses station 5408.

- A diversion channel along the west side of State Route 51 directs runoff north to station Indian Bend Wash at Sweetwater Avenue (FCDMC site 4643) from the mountains to the west.

- A diversion channel along the north side of Interstate 10 , and other channels, direct all runoff from the area bounded by I-10, I-17, the Agua Fria River, and the Arizona Canal to the Agua Fria River above stations Agua Fria River at Buckeye Road (FCDMC site 5403) and Agua Fria River at Avondale (09513970).

- A diversion channel along the north side of U.S. Highway 60 directs all runoff from the area bounded by US 60, Tempe Canal, and the East Maricopa Floodway to the Price Drain, which parallels State Route 101 and directs runoff to the Salt River above station Salt River at Jointhead Dam (09512170).

These modifications addressed the primary discrepancies between the existing stormwater drainage network and natural flowpaths, but other minor discrepancies may exist.

Three basin characteristics were used to represent urbanization: population density, percent imperviousness, and percent developed land cover. Mean population density was used as an explanatory variable for percent imperviousness to calculate a time-averaged percent imperviousness at each streamgaging station, whereas percent imperviousness was used as an explanatory variable in a regression analysis. Mean population density is reported as people per square kilometer, calculated for each watershed from block group-level data (U.S. Census Bureau, 2010). Mean percent imperviousness within each watershed was calculated from the 30-meter resolution 2001 NLCD data (Yang and others, 2003). In addition to imperviousness and percent developed land cover from the 2001 NLCD (Homer and others, 2007), additional explanatory variables were considered while trying to develop regression equations to predict flood peaks in urbanized watershed directly (as an alternative to applying an adjustment-regression equation to the rural-regression-predicted flood peaks). These were drainage area, mean basin elevation, calculated from the $1 / 3$ arc-second resolution (10-meter) USGS National Elevation Dataset, and mean annual precipitation (PRISM Climate Group, 2012). Further details about the calculation of these basin characteristics are in Paretti and others (2014b).

\section{Streamgaging Station Data}

Annual peak-flow data in urban areas are collected at streamgaging stations specifically installed for urban studies and at stations installed on large watersheds that originate outside urban areas. In addition to USGS stations, FCDMC and PCRFCD maintain streamgaging station networks as part of Automated Local Evaluation in Real Time (ALERT) networks for flood warning. FCDMC data begin in 1989 and 17 of the 25 stations considered for inclusion were used in the analysis. PCRFCD data begin in 1987 at the one urban site used in the analysis (FCDMC and PCRFCD also collect data at other non-urbanized stations; PCRFCD stations are primarily outside the urban region). At some streamgaging stations both USGS and FCDMC or PCRFCD have operated in the same or nearly the same location. In this case, station records have been combined to cover the longest possible period of record. Stage-discharge rating curves maintained by each respective agency were used, depending on the data source. These combined stations are indicated by station identifications ending in 99 . The individual stations that comprise the combined stations are provided in table 1.

\section{Nonstationarity Adjustment}

One difficulty in either approach to urban flood frequency analysis - developing adjustment-regression equations for rural peaks, or regression equations to predict urban peaks directly-is the typically nonstationary nature of urban development (nonstationarity is defined as a timeseries in which the underlying process has non-constant mean and [or] variance). The problem is especially prevalent in the Southwestern United States; Nevada and Arizona had the highest and second-highest percent population growth, respectively, between 2000 and 2010 (U.S. Census Bureau, 2010). The population density within the watershed area at every streamgaging station in the study has increased between 1970 and 2012 (table 1). At most stations, the largest increases in population density were between 1970 and 1980, and between 2000 and 2010. Except for the earliest-developed watersheds in the central parts of Phoenix and Tucson all of the watersheds in the present study have experienced significant changes in urbanization since the 1970s.

A common approach to addressing nonstationarity is to use watersheds and (or) periods where urbanization has been constant, often identified using a Mann-Kendall trend test (Helsel and Hirsch, 2002), to exclude watersheds or periods with nonstationary peak flows. This approach was utilized by Sauer and others (1983), who eliminated all streamgaging stations with an increase in imperviousness greater than 50 percent during the period of record. This approach was also taken by Southard (2010), Gotvald and Knaak (2011), and Gotvald and others (2012). For this study, stationarity was evaluated by applying a Mann-Kendall trend test to the record at each streamgaging station. The MannKendall test is typically used for relatively long time series; a 30-year peak-flow record is often considered the minimum adequate length for evaluating trends. Nevertheless, applying the test to all stations in the analysis resulted in only two 
instances where the null hypothesis, that there is no trend in streamflow, was rejected. The record lengths for these stations, FCDMC site 5543 and 09483010, were relatively short at 17 and 16 years, respectively, and the trend at station 09483010 is negative, with the magnitude of flood peaks decreasing during the period of record; therefore, no stations were removed from the analysis due to nonstationarity.

Time-averaged imperviousness was calculated at each streamgaging station based on the period of annual peak flow data, time-series data of population density, and a regression relation between percent imperviousness and population density. Ideally, average imperviousness would be identified directly from time-series maps of impervious area, but such data do not exist with the temporal extent needed. Instead, for each urban watershed, 2001 NLCD imperviousness area (Yang and others, 2003) was compared to 2000 population density (U.S. Census Bureau, 2010) to develop a locally weighted smoothing (Lowess) model (fig. 5). Then, the population density in each year that peak flows were recorded was interpolated from 1970, 1980, 1990, 2000, and 2010 population density data (U.S. Census Bureau, 2010). Finally, the percent imperviousness in each year was estimated from the Lowess model. For the limited amount of urban flood peak data before 1970, percent imperviousness is assumed to equal the 1970 value (table 1). Linear extrapolation is used to estimate percent imperviousness for flood peaks after 2010 .

\section{Rural-Regression Estimates}

The log-Pearson type III (LP3) distribution has been adopted as the standard flood-frequency model throughout the United States. Methods for fitting the moments (mean, standard deviation, and skew) of the LP3 distribution are described in the "Guidelines for Determining Flood Flow Frequency," known as Bulletin 17B (Interagency Advisory Committee on Water Data, 1982). Since publication, several improvements to Bulletin 17B have been suggested concerning the treatment of low-outlier, historical, and censored flood information (Stedinger and Griffis, 2008). The expected moments algorithm (EMA) used with the multiple Grubbs-Beck (MGB) test, explicitly accounts for these shortcomings (Cohn and others, 1997; Cohn and others, 2001; England and others, 2003). Of particular note for Arizona and other semiarid regions with large variability in annual maximum floods, the MGB test efficiently accounts for multiple potentially influential low-flows, which otherwise may have undue influence on the estimated magnitude of large, low-probability floods. An evaluation of the implications for replacing Bulletin 17B methods with EMA-MGB methods for Arizona streamgaging stations determined that predicted peak flows using EMA-MGB were neither consistently larger nor smaller than Bulletin 17B predictions, and that goodness-of-fit criteria indicated EMA-MGB provided a better representation of the peak flow data (Paretti and others, 2014a). Rural-regression estimates for the urban stations in this analysis were calculated using the LP3 distribution, fitted using EMA-MGB, from a recent analysis of data for Arizona and surrounding States (Paretti and others, 2014b).

For flood frequency analyses using Bulletin 17B methods and the LP3 distribution, the third moment, skew, is typically estimated as the weighted average of the value determined from the data at a streamgaging station (station skew) and an average regional value (regional skew). Regional skew can be estimated from maps interpolated from skewness coefficients at individual stations, or determined from regression analysis. As part of the flood frequency analysis for rural streamgaging stations in Arizona, a Bayesian generalized least squares regression analysis of regional skew was undertaken (Paretti and others, 2014b). No basin characteristics were discovered that explained variation in skew among stations, and a constant statewide skew was determined to be adequate. No studies have demonstrated that a regional skewness coefficient calculated for rural stations should be applicable to urban stations, and too few stations in the present study have sufficient long-term records to calculate a regional skew specifically for urban stations. Therefore, as with many previous studies (Inman, 1995; Moglen and Shivers, 2006; Gotvald and Knaak, 2011), no regional skew is used and the flood-frequency estimates are based on station skew only. For reference, the comparison of urban flood-frequency estimates with rural-regression estimates was repeated using a weighted average skew; visual inspection of the comparison plots (figs. 6-9) showed little difference.

The rural-regression equations for Arizona (Paretti and others, 2014b) are based on five regions - Western Basin and

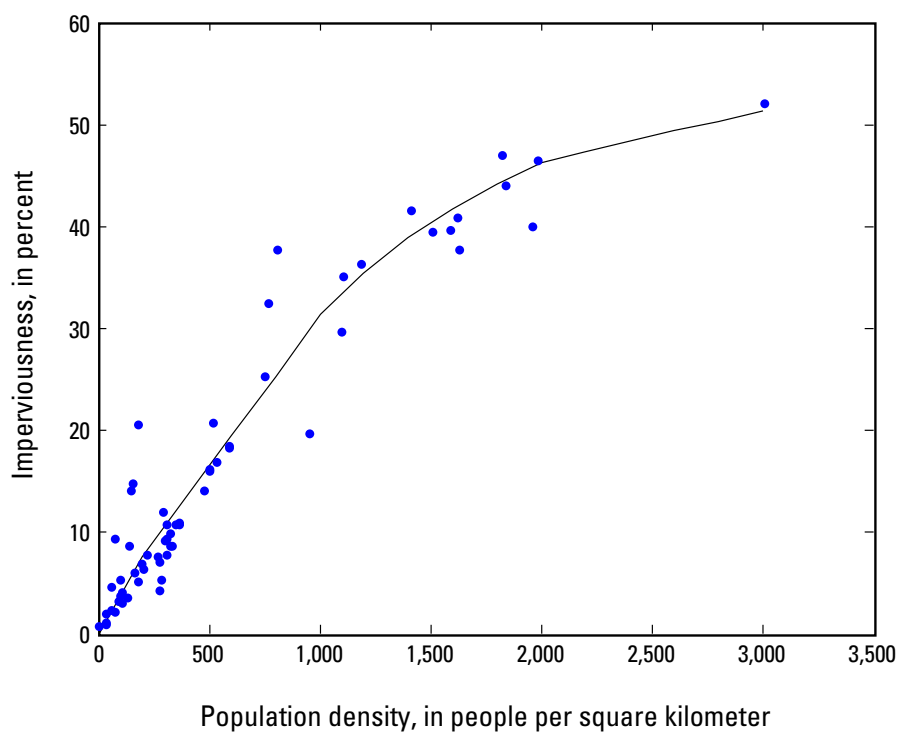

Figure 5. Graph showing locally weighted smoothing model relating population density from census data to impervious area for the urban streamgaging stations in the Phoenix and Tucson metropolitan areas, Arizona, included in the study. Census data from U.S. Census Bureau (2010). 
Range, Southeastern Basin and Range, Colorado Plateau, a Central Highlands region that covers the "Transition Zone" in the center of the State, and a separate high-elevation region that comprises stations above 7,500 feet elevation (fig. 1; note that Western and Southeastern Basin and Range, as well as Central Highlands, are informal names, only capitalized in this report for clarity). All of the urbanized streamgaging stations in this study are in either the Western or Southeastern Basin and Range regions. Tucson is entirely within the Southeastern Basin and Range region, and stations in the Phoenix area are mostly in the Western Basin and Range region but with a few stations in the eastern part of the metropolitan area located in the Southeastern Basin and Range region. Drainage area and mean annual precipitation are explanatory variables in the ruralregression equations for the Western Basin and Range region; drainage area is the only explanatory variable in the equations for the Southeastern Basin and Range region. The respective region at each streamgaging station is used to generate the ruralregression estimates of peak flows presented in the section, "Comparison with Rural Equations."

\section{Flood Frequency Estimates at Streamgaging Stations}

Peak-flow estimates for urban streamgaging stations in the analysis for the 50-, 20-, 10-, 4-, 2-, 1-, 0.5-, and 0.2-percent AEPs are given in table 2. The skewness coefficient ranges from -1.17 to 1.61 , and the mean and median coefficients are 0.08 and 0.05 , respectively. For comparison, the statewide mean skew for non-urbanized gages is -0.09 . Skewness coefficients were not correlated with either drainage area or percent imperviousness $\left(R^{2}\right.$ [coefficient of determination] values of 0.16 and 0.01 , respectively). Standard model error of the station predictions ranges from 29 to 150 percent for the 1-percent AEP peak flow; stations with large errors generally have large positive skew, short record lengths, or both. The median standard model error for all AEPs is 69 percent.

Many flood-frequency studies estimate flood peaks at a streamgaging station as a weighted average of the station prediction and the prediction from the rural-regression equations. The respective weight given to each estimate is determined by the uncertainty of the estimate. Based on the many previous studies that show increases in runoff from urbanized watersheds, no justification exists for applying the rural-regression equations to urbanized watersheds to determine a weighted average, and only station estimates are presented.

\section{Comparison with Rural Equations}

Two approaches were taken to evaluate whether the predicted flood-frequency for rural watersheds should be adjusted to account for urbanization. First, the rural-regression flood-frequency estimates were compared directly to the station estimates presented in table 2 . An increase in peak flows caused by urbanization should result in predicted peak flows at urbanized stations that are greater than those at rural stations, and urbanized watersheds with high amounts of imperviousness should have higher predicted peak flows than urbanized watersheds with little imperviousness. Second, an attempt was made to develop regression equations that predict flood flows for a given AEP specifically for urbanized stations, using imperviousness and other indicators of urbanization as explanatory variables. Using the methods in the user's manual for the USGS regression software Weighted-Multiple-Linear Regression Program (WREG; Eng and others, 2009), significant explanatory variables will be retained in the final regression equations, whereas variables with no explanatory power will be excluded.

Scatterplots show the comparison of station and ruralregression flood-frequency estimates (fig. 6). Each point on each plot represents the predicted flood peak at a streamgaging station for the indicated AEP; the $\mathrm{x}$-coordinate is the estimate from the rural-regression equations (Paretti and others, 2014b) and the $y$-coordinate is the estimate for the urbanized station (table 2). Points located below the diagonal 1:1 line (fig. 6) indicate that the rural-regression prediction is greater than the station prediction; points above the 1:1 line indicate the station prediction is greater.

In general, the plots show significant scatter, indicating the rural-regression equations are not good predictors of flood peaks at urban streamgaging stations. For the more frequent flood peaks with higher AEPs shown in figure $6 \mathrm{~A}$, many of the watersheds with higher imperviousness (as indicated by red coloring) plot above the 1:1 line, indicating the ruralregression equations are underestimating flood peaks. Likewise, watersheds with lower imperviousness (in blue) plot below the line. As the AEP decreases from 50 to 4 percent, for the stations with higher station estimates than rural-regression estimates (above the line), the station estimates generally decrease relative to the rural-regression estimate, so that all of the points shift downward relative to the line. This is an indication that urbanization has the greatest effect on smaller, more frequent flood peaks (that is, 50 percent and 20 percent AEP peaks), also shown in the analysis by Moglen and Shivers (2006). Although some amount of scatter about the line is expected because of uncertainty in the station estimates and error in the rural-regression model, the flood peaks for watersheds shown in figure $6 \mathrm{~A}$ with relatively higher imperviousness are mostly above the line, whereas the larger, less-frequent flood peaks in figure $6 B$ are generally centered about the line.

An alternative approach to the comparison of station estimates to rural-regression peak flow estimates is to evaluate the difference between the two as a function of percent imperviousness. If imperviousness were an adequate explanatory variable that describes the increase in flood peaks caused by urbanization, larger differences between station and rural-regression estimates would be expected for watersheds with higher imperviousness. Furthermore, more positive than negative differences would be expected. Scatter plots 


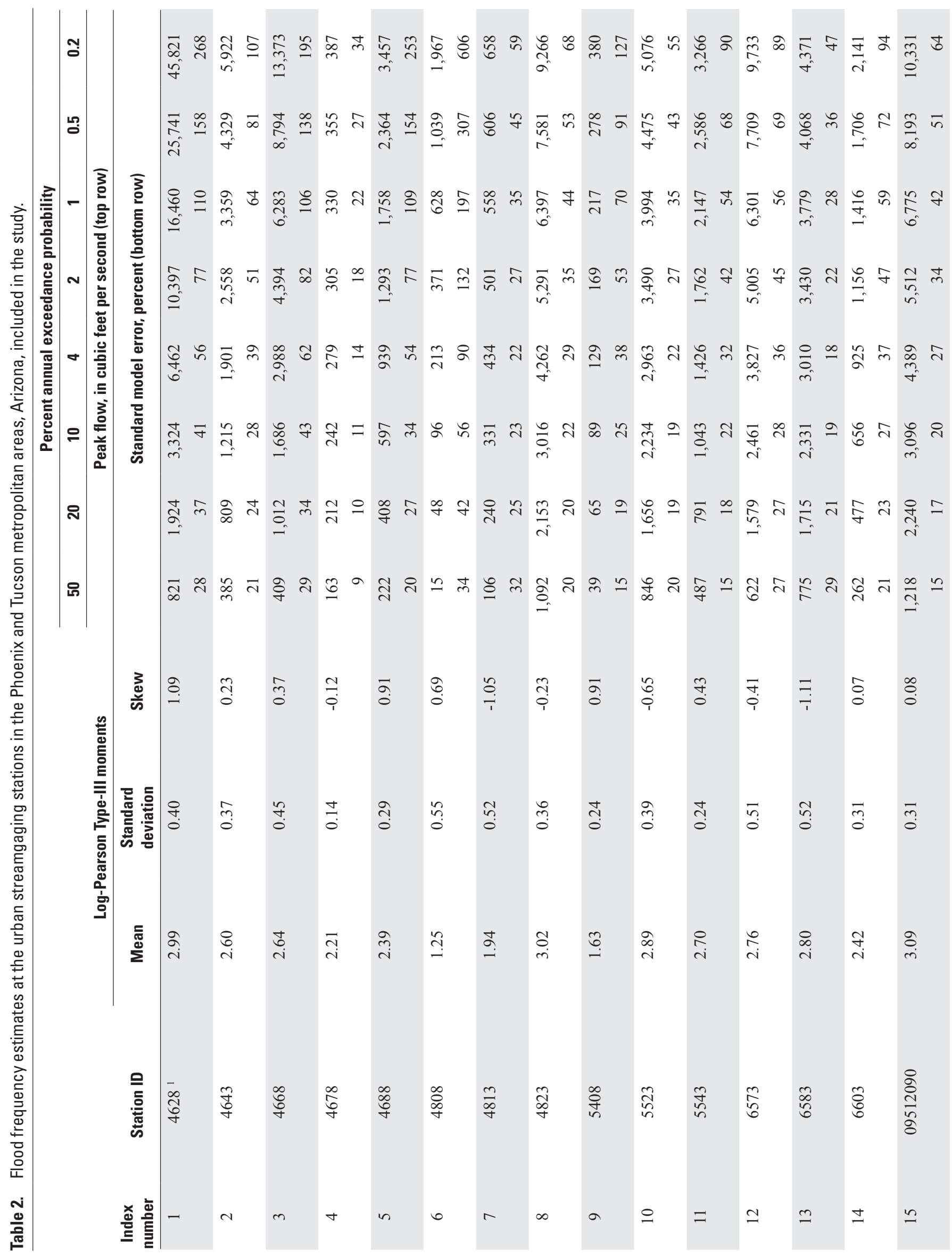




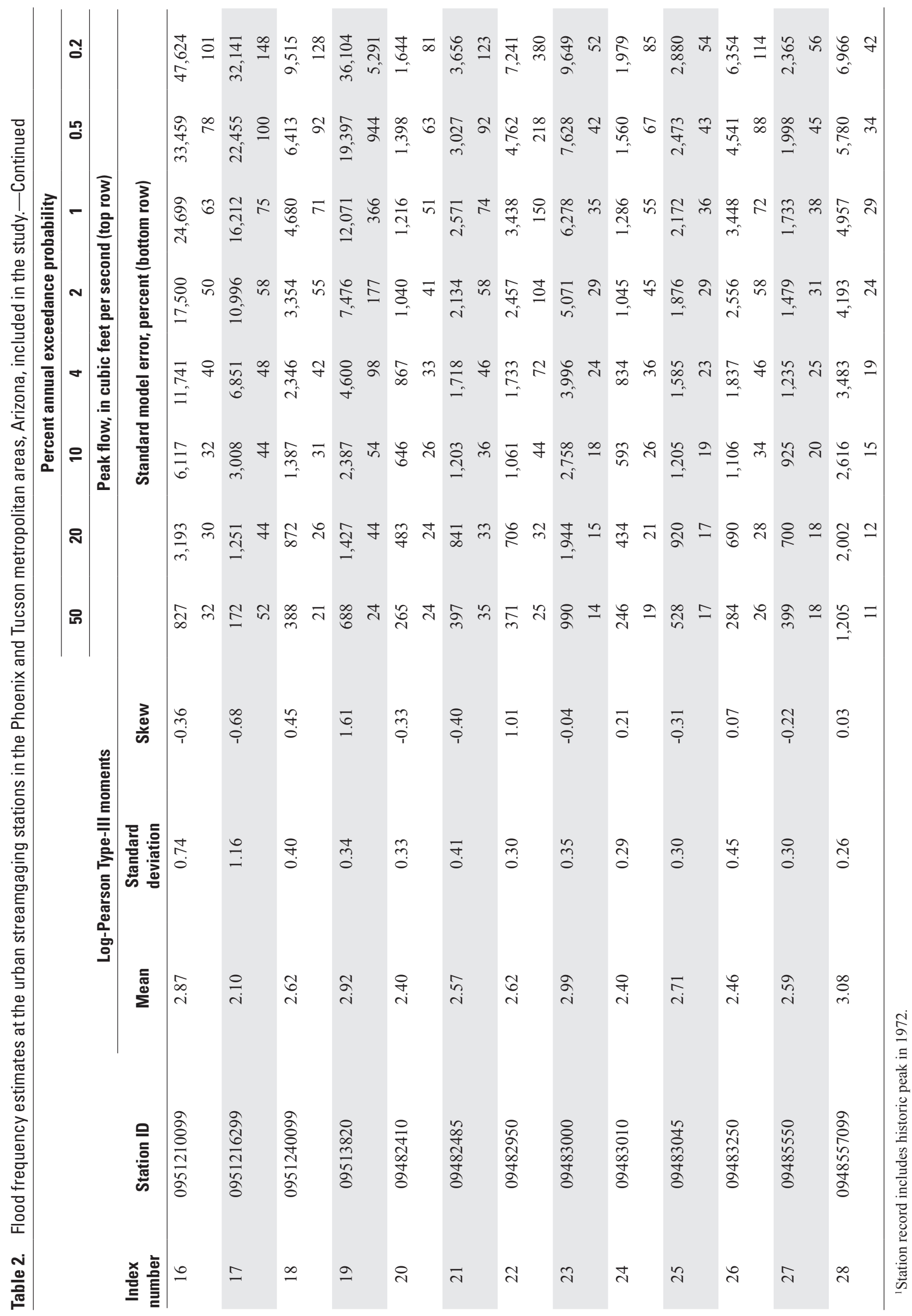



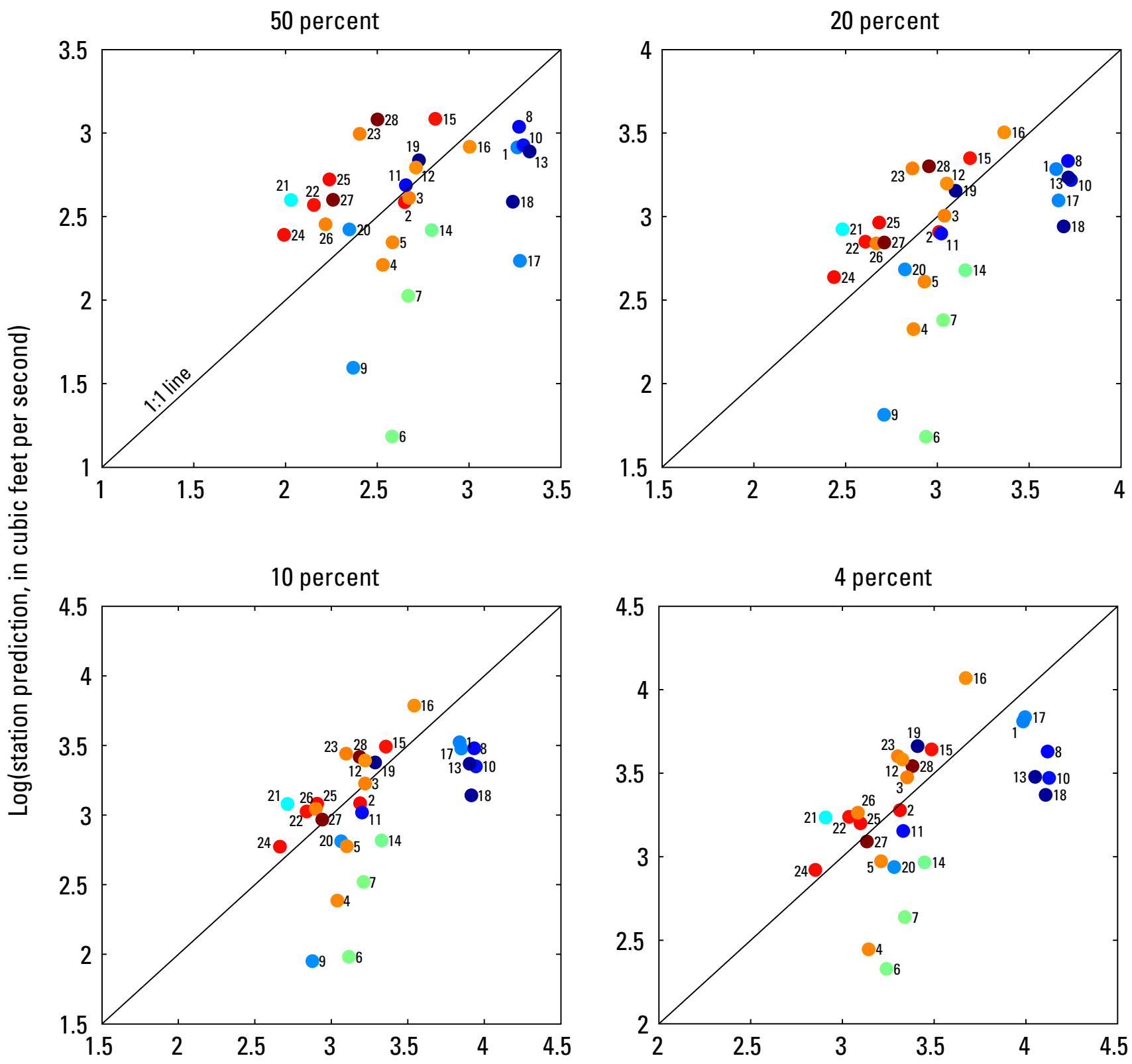

Log(regression prediction, in cubic feet per second)

EXPLANATION

Imperviousness, in percent

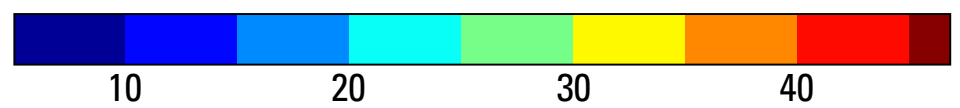

-9 Map ID—see table 1 and figs. 2 and 3

Figure 6. Scatterplots showing the difference between predicted flood peaks at the urban streamgaging stations in the Phoenix and Tucson metropolitan areas, Arizona, included in the study and predicted flood peaks from rural-regression equations. $A$, Comparison for 50-, 20-, 10-, and 4- percent annual exceedance probabilities (AEPs); B, comparison for 2-, 1-, 0.4-, and 0.2-percent AEPs. Numbers indicate the map ID from table 1. 
$\boldsymbol{B}$

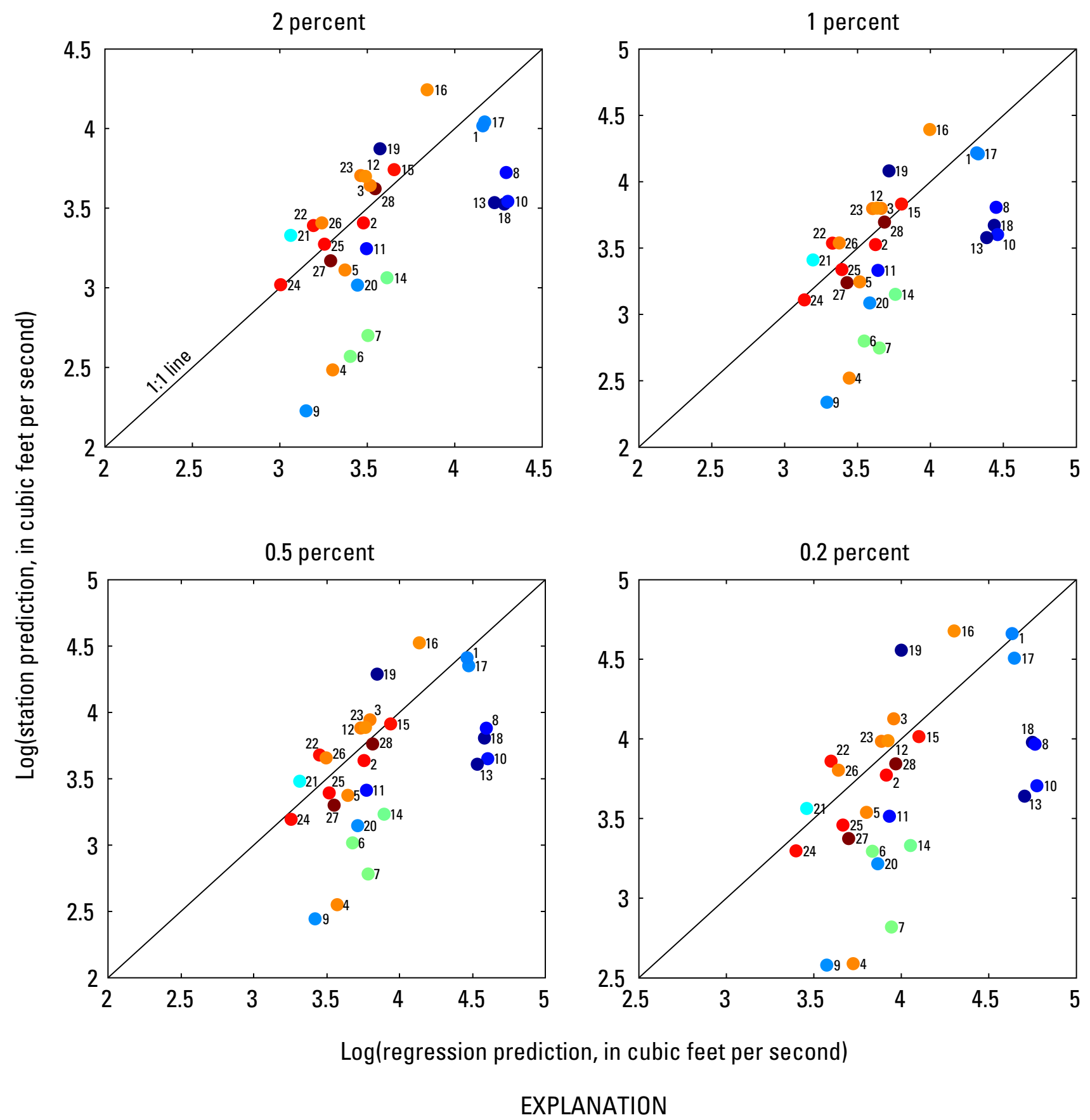

Imperviousness, in percent

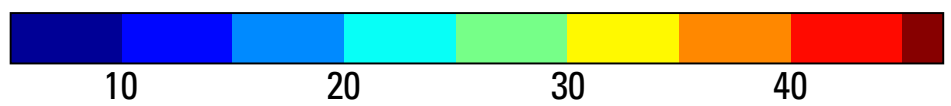

-9 Map ID—see table 1 and figs. 2 and 3

Figure 6.-Continued 

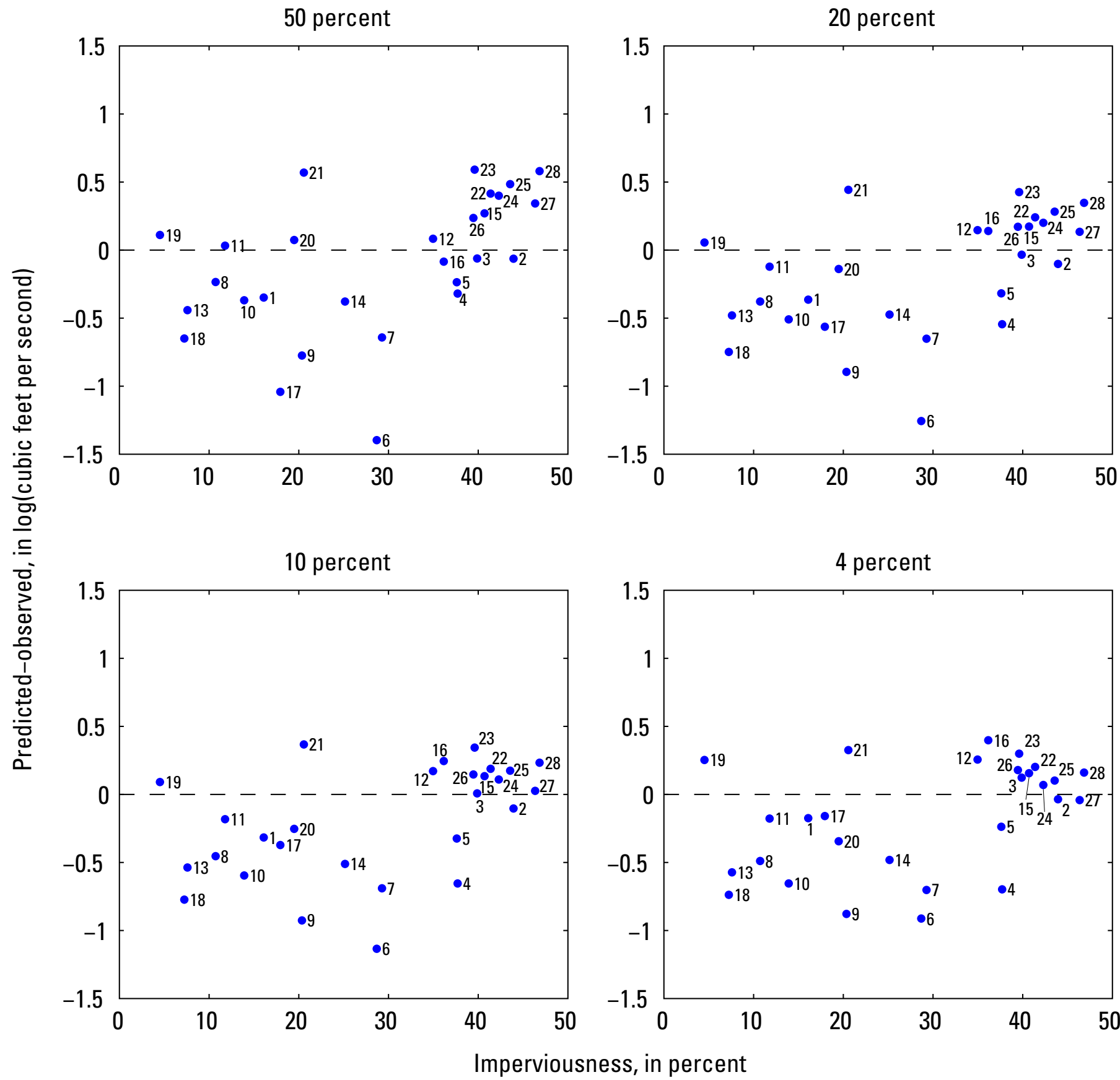

EXPLANATION

-9 Map ID—see table 1 and figs. 2 and 3

Figure 7. Scatterplots showing the difference between station and rural-regression flood-frequency estimates (residuals) versus watershed imperviousness. $A$, Comparison for 50-, 20-, 10-, and 4-percent annual exceedance probabilities (AEPs); $B$, comparison for $2-, 1-, 0.4-$, and 0.2-percent AEPs. Positive values indicate the station estimate at a streamgaging station is greater than and negative values indicate the estimate is less than the rural-regression estimate. Numbers indicate the map ID from table 1. 
B
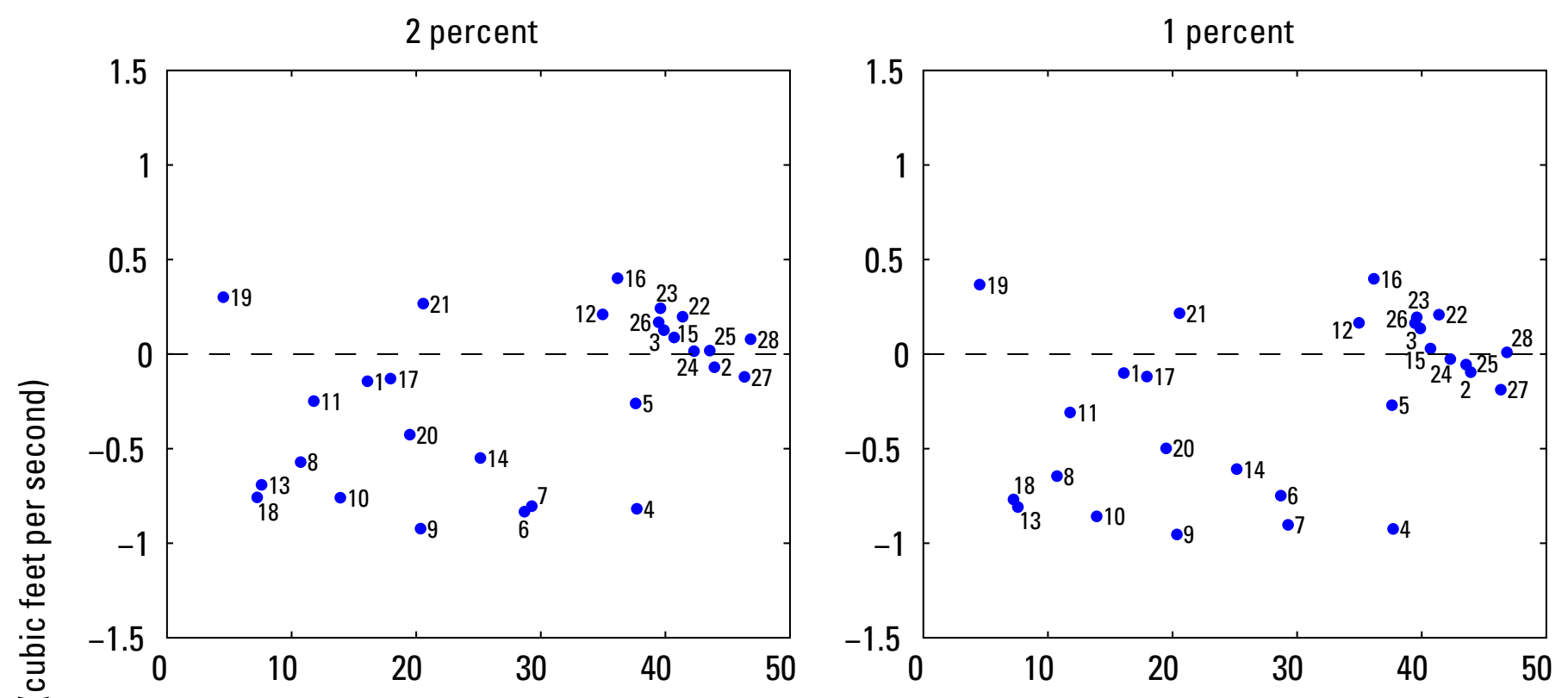

응
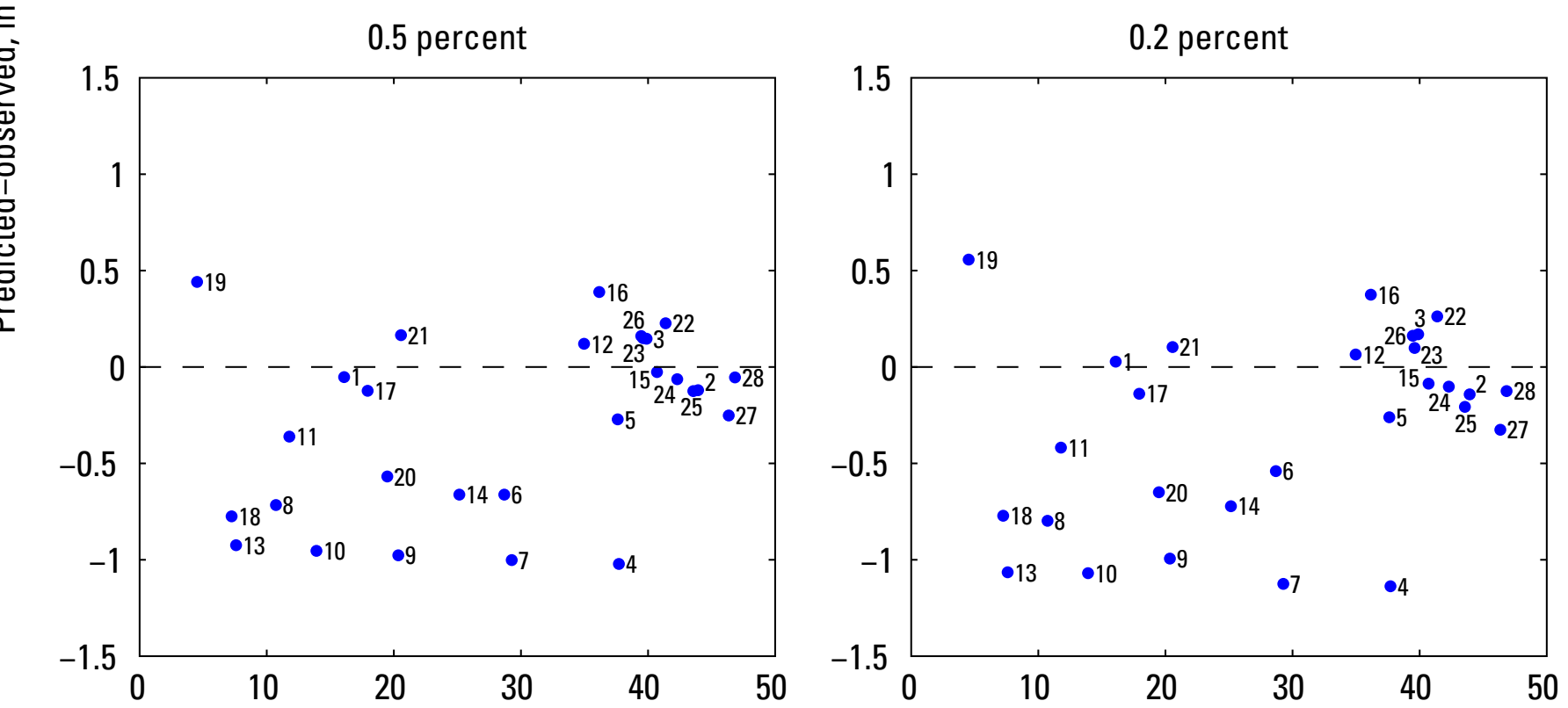

Imperviousness, in percent

\section{EXPLANATION}

-9 Map ID—see table 1 and figs. 2 and 3 
of the difference between the two estimates versus percent imperviousness for the watersheds in the study do not show any relationship between the difference in the estimates and imperviousness, indicating that imperviousness is not a suitable explanatory variable (fig. 6). For lower AEP flood peaks (fig. $7 B$ ), nearly all of the differences are negative, indicating the rural-regression estimate is smaller than the station estimate. For the 1-percent AEP flood, 21 of 28 differences are negative. The differences between the station and rural-regression estimates appear to be more heavily influenced by factors other than imperviousness within each watershed.

A regression analysis was undertaken to determine if a particular combination of basin characteristics, including imperviousness, could better estimate flood peaks in urbanized watersheds as compared to using the rural-regression equations alone. Ordinary least squares procedures as implemented in the USGS regression software WREG (Eng and others, 2009) were used to fit regression equations relating flood peaks at urbanized streamgaging stations to basin characteristics, including drainage area, elevation, precipitation, imperviousness, and developed land cover. Although weighted or generalized least squares are preferred when data used in the regression analysis are not uniformly weighted and (or) independent, ordinary least squares is sufficient to determine whether the explanatory variables chosen are significant. WREG identifies significant explanatory variables by evaluating the $T$ value statistic for each characteristic:

$$
T \text { value }=\frac{\beta_{k}}{\left(\operatorname{Var} \beta_{k}\right)^{1 / 2}},
$$

where $\beta_{k}$ is the predicted coefficient of the $k$ th basin characteristic and $\operatorname{Var} \beta_{k}$ is the covariance of $\beta_{k}$, taken from the covariance matrix of the regression parameters. The $T$ value statistic is assumed to follow a Student's $t$ distribution, and the probability, or $p$-value, that the null hypothesis $\left(H_{0}\right.$, the model parameter is equal to zero) should be rejected can be calculated. Regression parameters with $p$-values less than 0.05 are deemed to be significant and are included in the final regression equation.

The regression analysis indicated that only drainage area and elevation were significant explanatory values for 50-, 20-, and 10-percent AEP flood peaks, and only drainage area was significant for 4-, 2-, 1-, 0.5-, and 0.2-percent AEP flood peaks. Several subsets of stations were also considered, including only small watersheds, only Phoenix or Tucson watersheds, and only watersheds with long periods of record. Neither of the urban-related explanatory variables, percent imperviousness or percent developed land cover, were significant in any of the regression equations. Using $R^{2}$ as a diagnostic statistic, the regression equations developed specifically for the urbanized watersheds had less explanatory power than the rural regression equations (table 3 ; lower $R^{2}$ values indicate less explanatory power in the regression). Pseudo- $R^{2}$ is presented for the rural-regression equations (Paretti and others, 2014b), which were developed using generalized least squares and therefore required a different error statistic (Griffis and Stedinger, 2007). Based on the relatively poor performance of the regression equations developed for the urbanized stations, and the lack of significance for independent variables that describe urbanization, the use of separate equations to predict flood peaks in urbanized watersheds is not justified.

\section{Comparison with Adjustment Equations from Moglen and Shivers (2006)}

The comparison of streamgaging station estimates with the rural-regression equations indicates that flood peaks in urbanized watersheds are not systematically larger than peaks in rural watersheds, especially for lower AEP floods. A follow-up analysis was made to determine the effect of urban-adjustment regression equations on estimated flood peaks. Equations for adjusting rural flood peaks for urbanized watersheds across the United States are presented in Moglen and Shivers (2006). Using the methodology in Moglen and Shivers (2006), flood peaks estimated for rural watersheds are adjusted upward using adjustment-regression equations based on basin characteristics indicative of urbanization. Equations are presented using various explanatory variables, including percent imperviousness or population density; scaled imperviousness or population density, which are nonlinear functions of these two variables; and imperviousness or population density distribution models, which use the difference between the 10th and 90th percentiles of these two variables. Seven sets of adjustment equations are presented, each with equations for the 50-, 20-, 10-, 4-, 2-,

Table 3. Coefficient of determination for the regression equations developed for the urban streamgaging stations in the Phoenix and Tucson metropolitan areas, Arizona, included in the study, and pseudo- $R^{2}$ for the applicable regional rural-regression equations.

[Data from Paretti and others (2014b). $R^{2}$, coefficient of determination]

\begin{tabular}{|c|c|c|c|c|c|c|c|c|}
\hline \multirow[b]{2}{*}{ Regression Model } & \multicolumn{8}{|c|}{$R^{2}$ by Annual Exceedance Probability ${ }^{1}$} \\
\hline & 50 & 20 & 10 & 4 & 2 & 1 & 0.5 & 0.2 \\
\hline Urban & 36 & 42 & 42 & 32 & 31 & 29 & 27 & 23 \\
\hline Rural Southeastern Basin and Range region & 84 & 90 & 92 & 92 & 91 & 91 & 90 & 88 \\
\hline
\end{tabular}

\footnotetext{
${ }^{1} R^{2}$ for rural regression models is psuedo $R^{2}$ (Eng and others, 2009).
} 
1-, and 0.2-percent AEPs. Performance metrics for all of the equations were largely similar, and although an imperviousness distribution model was determined to be best, a simple

imperviousness model performed nearly as well. Therefore, the flood-frequency estimates at the streamgaging stations presented in table 2 are compared to the simple imperviousness equations presented by Moglen and Shivers (2006), which have the form:

$$
U Q_{p}=c_{1} \times R Q_{p}^{c_{2}} \times(I A+1)^{c_{3}},
$$

where

$$
\begin{aligned}
U Q_{p} & \begin{array}{r}
\text { is the adjusted peak flow estimate for a par- } \\
\text { ticular P-percent AEP, }
\end{array} \\
R Q_{p} & \begin{array}{r}
\text { is the equivalent rural-regression equation } \\
\text { estimate for that AEP, }
\end{array} \\
c_{1}, c_{2}, \text { and } c_{3} & \begin{array}{r}
\text { are coefficients identified using least squares } \\
\text { regression (table } 4), \text { and }
\end{array} \\
I A & \begin{array}{l}
\text { is percent imperviousness, between } 0 \text { and } 99 . \\
\text { One is added to } I A \text { to account for the zero- } \\
\text { percent imperviousness case. }
\end{array}
\end{aligned}
$$

Scatterplots of station estimates versus the adjusted rural-regression estimates clearly show that the urbanization adjustment is higher than the station estimate for nearly every station for every AEP (fig. 8), and the regression equation residuals are not correlated with imperviousness (fig. 9). Because the adjustment equation includes impervious area as an explanatory variable, the difference in the rural-regression estimate and the adjusted estimate is greatest for stations with greater percent imperviousness. As with the comparison of station estimates versus rural-regression estimates, the adjusted estimates are relatively higher than the station estimates for higher AEP flood peaks than for lower AEP peaks (figs. $8 A$ and $8 B$ ). Based on the watersheds used in this analysis, the upward adjustment of flood peaks predicted by rural-regression equations based on urbanization factors does not appear to be warranted.

\section{Drainage Area and Accuracy}

Accurate flood-frequency estimates require high-quality data collected over relatively long periods of time (Interagency Advisory Committee on Water Data, 1982). An example of the complicating effect of short station records and uncertainty in basin characteristics and within-basin storage in urban areas is provided by the five streamgaging stations used in the analysis that are located on Indian Bend Wash in Scottsdale and Tempe (table 1; map IDs 1, 2, 15, 16, 17). The contributing drainage areas for these six stations range from 11.7 to 216.3 square miles, but the predicted 1-percent AEP peak flows do not uniformly increase with increasing drainage area as indicated by the rural-regression equations. Between Indian Bend Wash at Scottsdale (0951210099; map ID 16) and Indian Bend Wash at McDonald Dr. (FCDMC site 4628; map ID 1), a distance of
Table 4. Coefficients for the simple imperviousness model.

[Data from Moglen and Shivers (2006). AEP, Annual exceedance probability; $c_{1}, \mathrm{c}_{2}$, and $c_{3}$, model coefficients]

\begin{tabular}{cccl}
\hline AEP & $\boldsymbol{c}_{\mathbf{1}}$ & $\boldsymbol{c}_{\mathbf{2}}$ & \multicolumn{1}{c}{$\boldsymbol{c}_{\mathbf{3}}$} \\
\hline 50 & 2.614 & 0.859 & 0.172 \\
20 & 2.866 & 0.862 & 0.147 \\
10 & 2.827 & 0.866 & 0.128 \\
4 & 2.965 & 0.870 & 0.102 \\
2 & 3.080 & 0.873 & 0.0825 \\
1 & 3.206 & 0.876 & 0.0628 \\
0.2 & 3.541 & 0.883 & 0.0166 \\
\hline
\end{tabular}

about 1 mile, the drainage area increases from 59.8 to 201.6 square miles (table 1), respectively, but the 1-percent AEP estimate based only on the stations records decreases from 24,700 to 8,250 cubic feet per second. The difference is explained in part by the different periods of record at each station. The record at the upstream station (Indian Bend Wash at Scottsdale, 0951210099) begins in 1970, and includes the flood-ofrecord in 1972-21,000 cubic feet per second. The systematic record at the downstream-station (Indian Bend Wash at McDonald Dr., FCDMC site 4628) begins in 1998 and the largest flood is 3,728 cubic feet per second, in 2006. The flood frequency estimates are much smaller at the downstream station because no large floods have occurred during the period of record. Therefore, the historical peak in 1972 was added to the station record for FCDMC site 4628 as a censored observation between 15,000 and 20,000 cubic feet per second; a non-exceedance threshold of 15,000 cubic feet per second was added for years 1973-97 for the EMA-MGB analysis. This causes the predicted 1-percent AEP estimate to increase from 8,250 to 16,460 cubic feet per second and is more consistent with the estimates for streamgaging stations that include the 1972 peak.

Because of the large increase in drainage area between streamgaging stations 0951210099 and 4628 , the rural regression equations predict much larger peak flows at the downstream station than the upstream station: 17,250 and 9,700 cubic feet per second, respectively. The concurrent annual peaks measured during the period of concurrent record at these two stations, however, are nearly identical (fig. 10). The absence of a large increase in discharge at the downstream stations, despite the large increase in drainage area, indicates that the contributing watershed area is poorly defined and (or) significant detention exists within the drainage area that lies between the stations. The additional contributing area at the downstream station lies primarily to the northeast of the Central Arizona Project Aqueduct in northeast Scottsdale, behind which significant storage exists. Storm runoff from this area must travel southeast along the upstream side of the Central Arizona Project Aqueduct, down ephemeral channels emanating from the McDowell 
$\boldsymbol{A}$
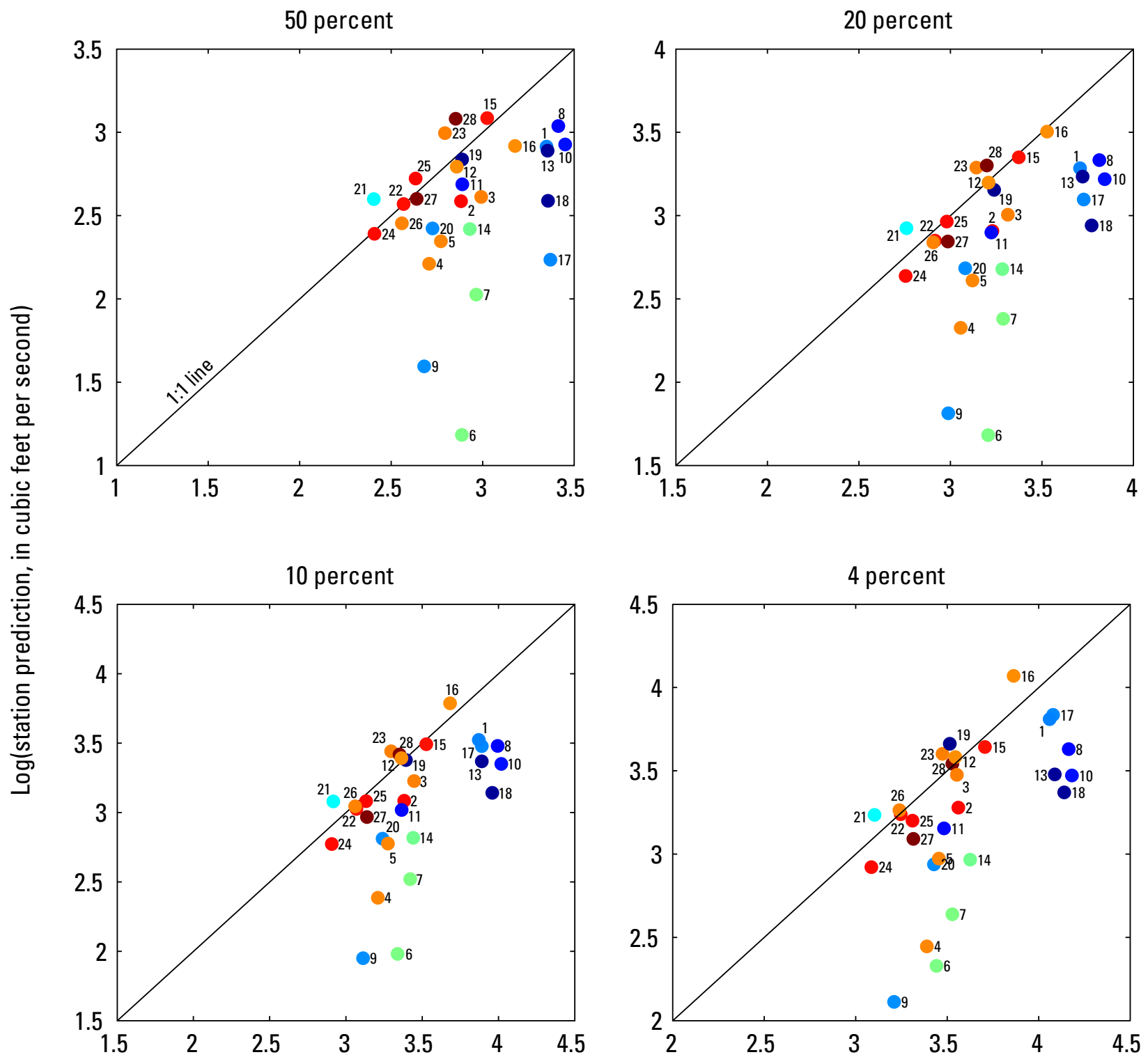

Log(Moglen and Shivers [2006] prediction, in cubic feet per second)

\section{EXPLANATION}

Imperviousness, in percent

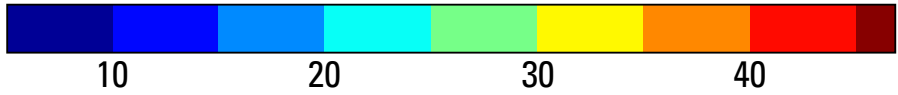

-9 Station index number-see table 1 and figs. 2 and 3

Figure 8. Scatterplots showing the difference between predicted flood peaks at urban streamgaging stations in the Phoenix and Tucson metropolitan areas, Arizona, included in the study and predicted flood peaks from rural-regression equations adjusted for urbanization. A, Comparison for 50-, 20-, 10-, and 4-percent annual exceedance probabilities (AEPs); $B$, comparison for 2-, 1-, and 0.2-percent AEPs (adjustment equations for 0.5-percent AEP estimates are not published in Moglen and Shivers [2006]). Numbers indicate the map ID from table 1. 
B
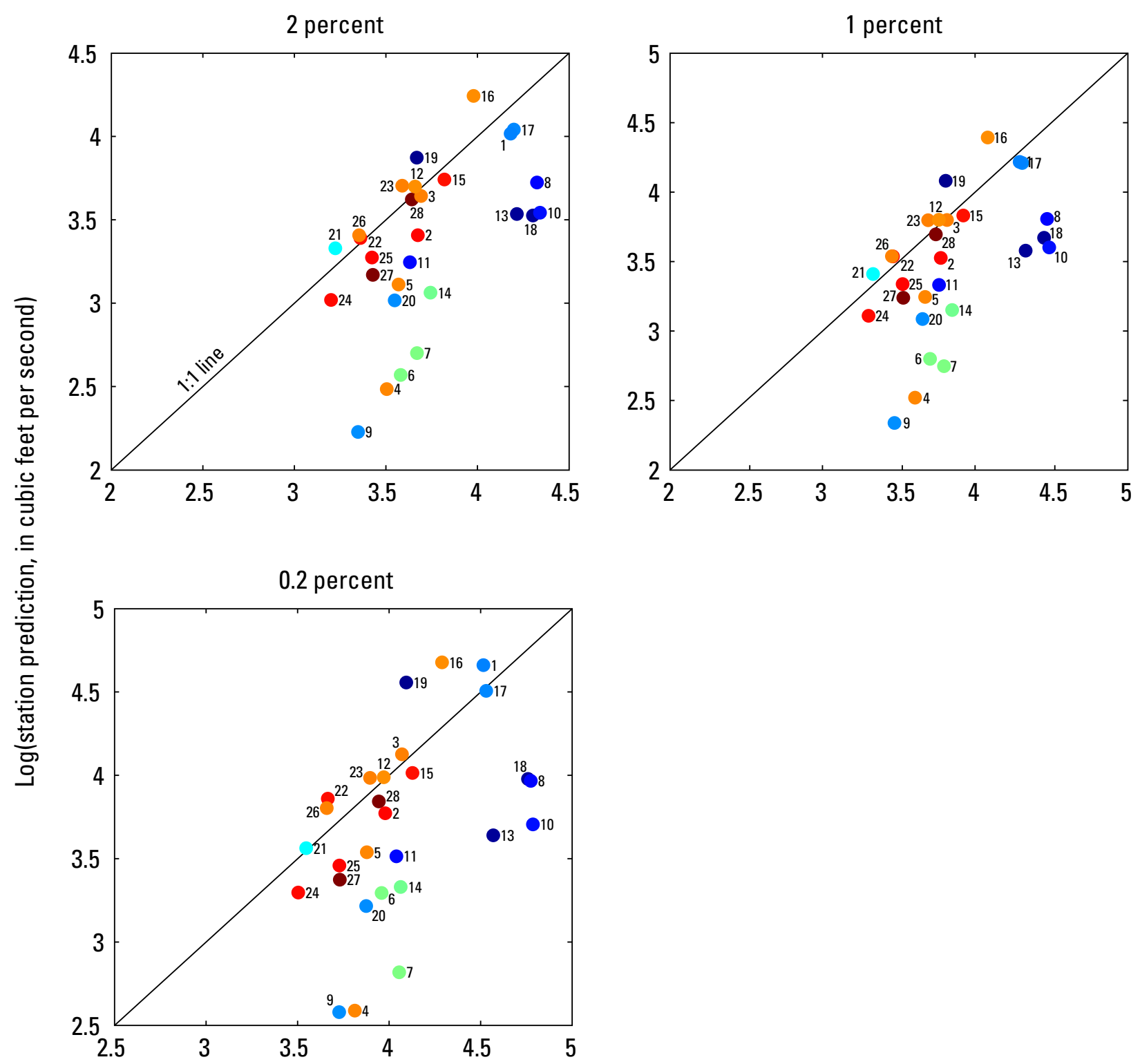

Log(Moglen and Shivers [2006] prediction, in cubic feet per second)

\section{EXPLANATION}

Imperviousness, in percent

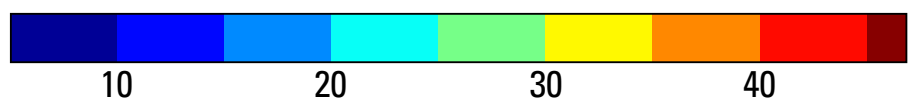

-9 Station index number-see table 1 and figs. 2 and 3

Figure 8.-Continued 

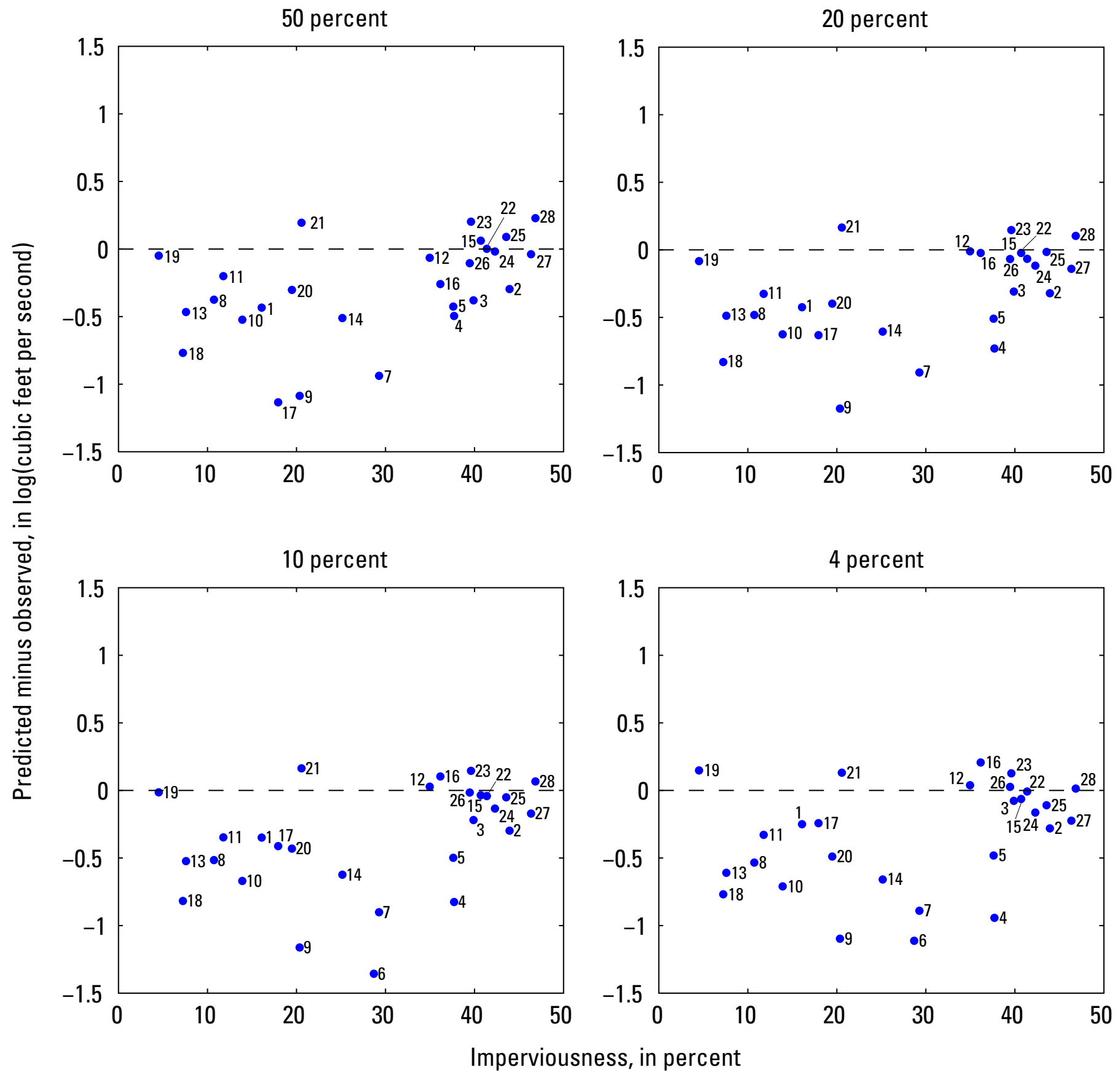

\section{EXPLANATION}

-9 Map ID—see table 1 and figs. 2 and 3

Figure 9. Scatterplots showing the difference between station and rural-regression flood-frequency estimates adjusted for urbanization (residuals) versus watershed imperviousness. $A$, Comparison for 50-, 20-, 10-, and 4-percent annual exceedance probabilities (AEPs); $B$, comparison for 2-, 1-, and 0.2-percent AEPs (adjustment equations for 0.5-percent AEP estimates are not published in Moglen and Shivers [2006]). Positive values indicate the station estimate at a streamgaging station is greater than and negative values indicate the estimate is less than the rural-regression estimate. Numbers indicate the map ID from table 1. 
B
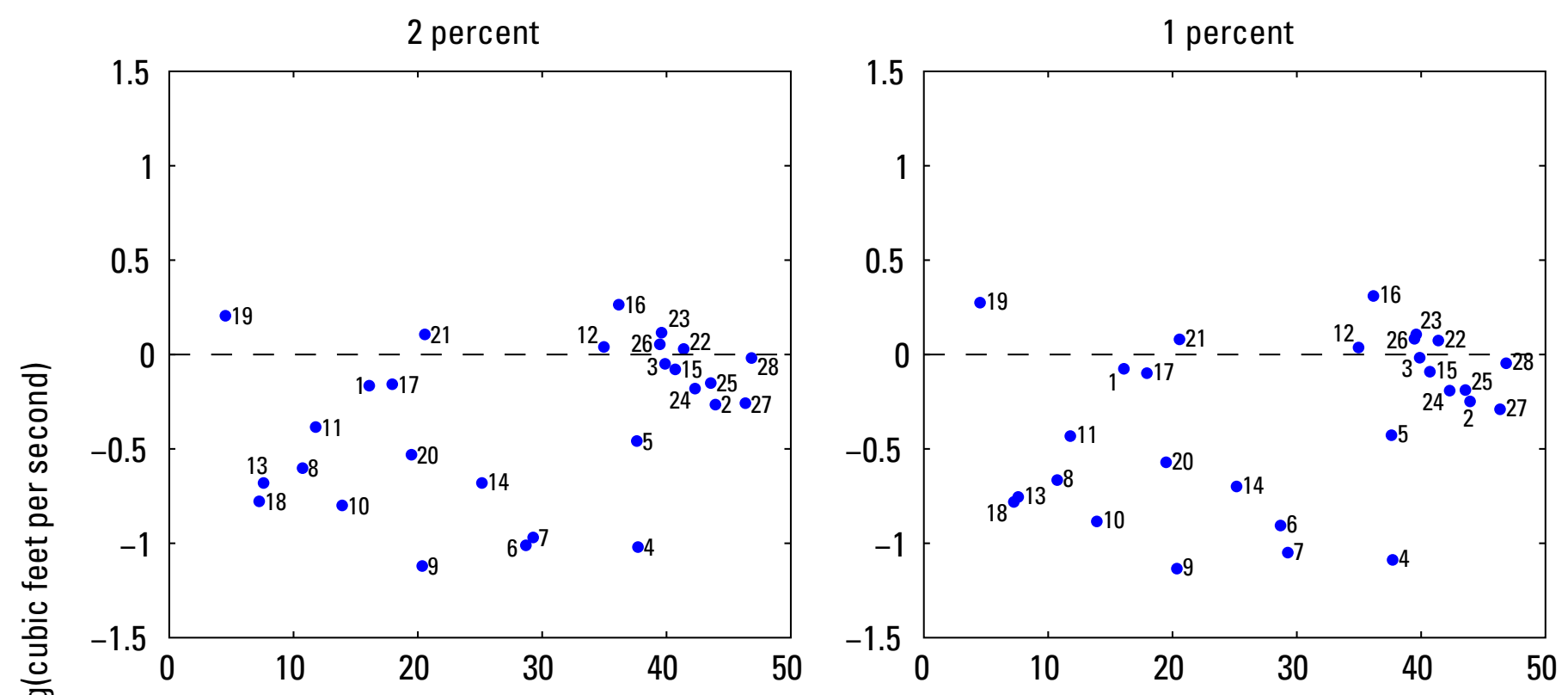

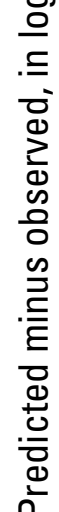

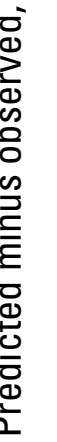

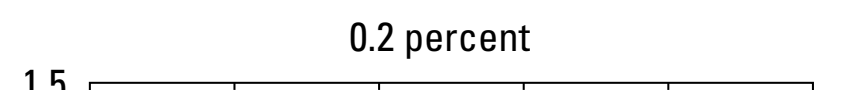

\section{2 percent}

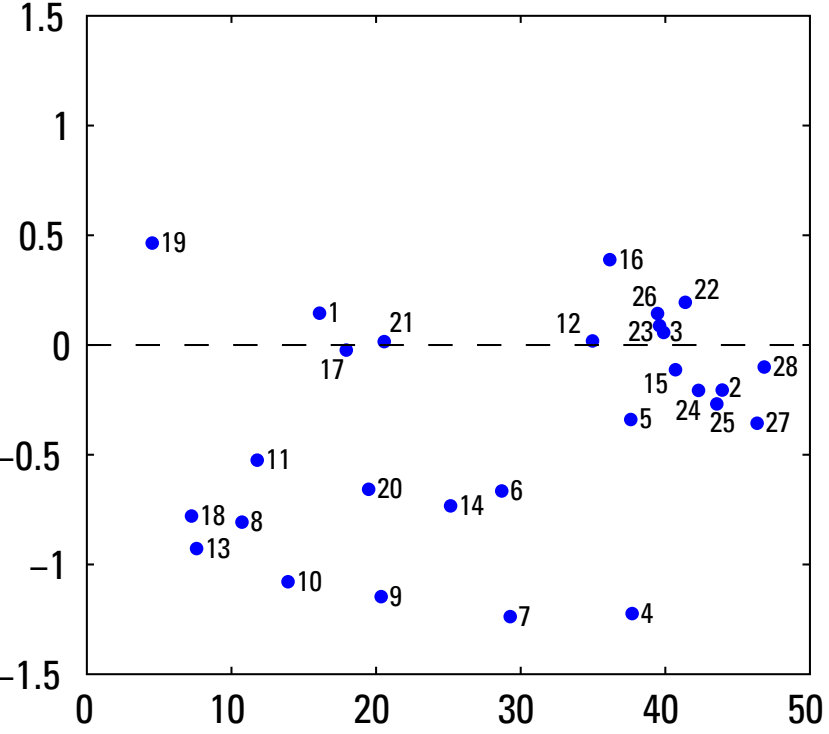

Imperviousness, in percent

\section{EXPLANATION}

-9 Map ID—see table 1 and figs. 2 and 3 


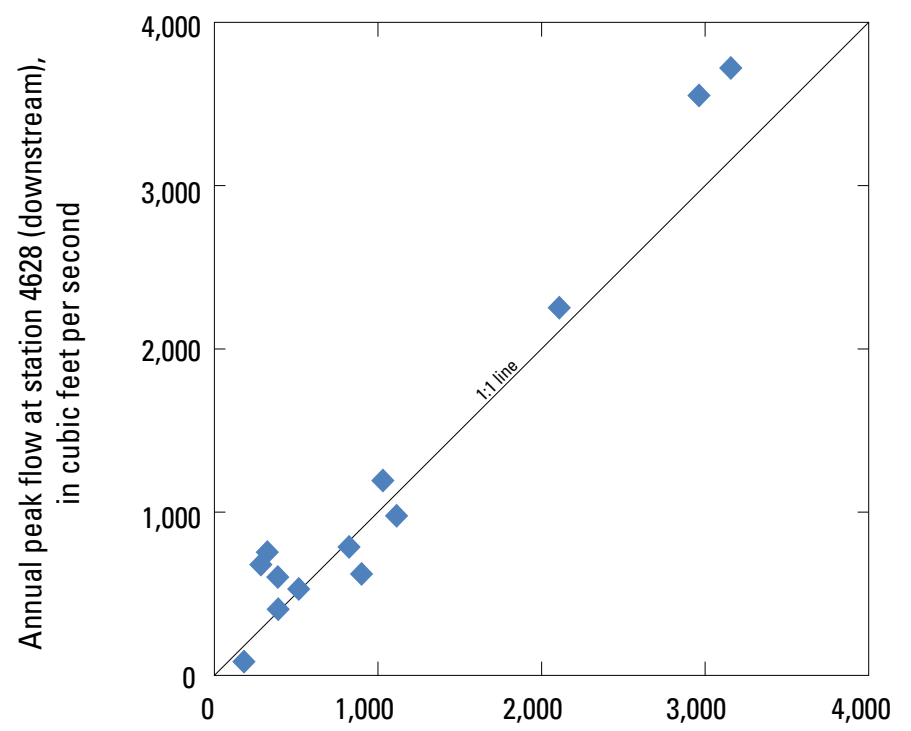

Annual peak flow at station 0951210099 (upstream), in cubic feet per second

Figure 10. Graph showing annual peak flows for two streamgaging stations on Indian Bend Wash near Phoenix, Arizona.

Mountains, and finally to the west along the upstream side of a second canal. The result is that much of the potential watershed area is noncontributing, and for relatively small peak flows the contributing watershed area is smaller than the total watershed area.

Considering the large variability in peak flows among different watersheds, and the lack of relation between flood peaks estimated using the LP3 distribution and urban basin characteristics such as percent imperviousness, the magnitude of flood peaks in any particular watershed appear to be determined largely by other factors. One possible explanatory variable is the amount of retention and detention storage within the watershed. This is particularly true for smaller watersheds that might be largely or entirely urbanized but also have substantial constructed storage. Furthermore, the small sample size of streamgaging stations in the present study does not represent every type and degree of urbanization in the region. In particular, urban watersheds with relatively high impervious area and long station records are located mostly in older neighborhoods, whereas newer developments generally have larger houses, smaller building lots, and therefore relatively higher amounts of impervious area. Unfortunately, accurate information about the amount and type of storage within a watershed is difficult to obtain, and in particular, is not available through remote sensing imagery. Therefore the decision whether to use the rural flood frequency equations to predict flood peaks in urban areas must be approached with caution, and an effort needs to be made by the user to determine how well the watersheds in question are represented by the watersheds in the present study.

\section{Summary and Conclusions}

This report presents an evaluation of flood-frequency estimates at urbanized streamgaging stations in Phoenix and Tucson, Arizona. The watersheds fall primarily into two categories: large watersheds, with headwaters outside of the urbanized region, and small watersheds that are more fully urbanized. The rural-regression equations developed for Arizona provided relatively poor predictions of peak flows in urbanized watersheds, particularly for small watersheds. Reasons for this are both the relatively little data available for the analysis and the much more heterogeneous conditions in urban watersheds than rural watersheds, in particular the diversity of stormwater retention structures. Comparison of the flood peaks estimated at each streamgaging station with the rural-regression-predicted flood peaks adjusted for urbanization using equations indicates that in general flood peaks in the study area do not need to be revised upward using the adjustment-regression equations. At nearly every station in the study, the adjusted rural peaks were greater than the flood peaks estimated using data at the individual station.

Although imperviousness was not determined to be an explanatory variable for the prediction of flood peaks from urban watersheds that is not to say that imperviousness has no effect. Rather, the particular streamgaging stations used in the analysis were not unduly influenced by imperviousness. Several previous studies have demonstrated that imperviousness can be an important factor. Therefore, the practitioner that wishes to predict flood peaks in urban basins is encouraged to conduct a careful examination of the watershed to determine the extent of within-basin floodwater storage before declining to apply an urban adjustment to rural-regression flood-frequency estimates.

Relatively little data were available for the analysis presented in this report, primarily because the long-term streamgaging stations in urban areas in Phoenix and Tucson are concentrated on the largest channels for which a substantial area of the upstream watershed is not urbanized. Small-watershed streamgaging stations are generally installed for specific studies and not maintained for the sake of long-term records. Nonetheless, the present study represents the most complete compilation to date of peakflow data to estimate flood-frequency in urban watersheds in Arizona, and provides appropriate error estimates for floodfrequency estimates at streamgaging stations.

\section{References Cited}

Adams, D.K., and Comrie, A.C., 1997, The North American Monsoon: Bulletin of the American Meteorological Society, v. 78 , p. 2197-2213.

Brabec, E., Schulte, S., and Richards, P.L., 2002, Impervious surfaces and water quality-A review of current literature and its implications for watershed planning: Journal of Planning Literature, v. 16, no. 4, p. 499-514. 
City of Scottsdale, 1985, Indian Bend Wash: The City of Scottsdale, Communications and Public Affairs, 97 p., accessed May 27, 2014, at http://www.scottsdaleaz.gov/ Assets/Public+Website/parks/IndianBendWashBook.pdf.

Cohn, T.A., Lane, W.L., and Baier, W.G., 1997, An algorithm for computing moments-based flood quantile estimates when historical flood information is available: Water Resources Research, v. 33, p. 2089-2096.

Cohn, T.A., Lane, W.L., and Stedinger, J.R., 2001, Confidence intervals for expected moments algorithm flood quantile estimates: Water Resources Research, v. 37, no. 6, p. 1695-1706.

Eng, Ken, Chen, Yin-Yu, and Kiang, J.E., 2009, User's guide to the weighted-multiple-linear-regression program (WREG version 1.0): U.S. Geological Survey Techniques and Methods, book 4, chap. A8, 21 p., available at http://pubs.usgs.gov/tm/tm4a8/.

England, J.F., Jr., Salas, J.D., and Jarret, R.D., 2003, Comparisons of two moments-based estimators that utilize historical and paleoflood data for the log Pearson type III distribution: Water Resources Research, v. 39, no. 9, p. 1243.

Eychaner, J.H., 1984, Estimation of magnitude and frequency of floods in Pima County, Arizona, with comparisons of alternative methods: U.S. Geological Survey WaterResources Investigations Report 84-4142, 71 p.

Griffis, V.W., and Stedinger, J.R., 2007, The use of GLS regression in regional hydrologic analyses: Journal of Hydrology, v. 344, p. 82-95.

Gotvald, A.J., Barth, N.A., Veilleux, A.G., and Parrett, C., 2012, Methods for determining magnitude and frequency of floods in California, based on data through water year 2006: U.S. Geological Survey Scientific Investigations Report 2012-5113, 38 p., 1 pl., available at http://pubs.usgs.gov/sir/2012/5113/.

Gotvald, A.J., and Knaak, A.E., 2011, Magnitude and frequency of floods for urban and small rural streams in Georgia, 2008: U.S. Geological Survey Scientific Investigations Report 2011-5042, 39 p., available at http://pubs.usgs.gov/sir/2011/5042/.

Helsel, D.R., and Hirsch, R.M., 2002, Statistical methods in water resources: U.S. Geological Survey Techniques of Water Resources Investigations, book 4, chap. A3, 522 p., available at http://pubs.usgs.gov/twri/twri4a3/.

Homer, C., Dewitz, J., Fry, J., Coan, M., Hossain, N., Larson, C., Herold, N., McKerrow, A., VanDriel, J.N., and Wickham, J., 2007, Completion of the 2001 National Land Cover Database for the conterminous United States: Photogrammetric Engineering and Remote Sensing, v. 73, no. 4, p. $337-341$.
Inman, E.J., 1995, Flood-frequency relations for urban streams in Georgia-1994 update: U.S. Geological Survey WaterResources Investigations Report 95-4107, 27 p.

Interagency Advisory Committee on Water Data, 1982, Guidelines for determining flood-flow frequency, Bulletin 17B of the Hydrology Subcommittee, Office of Water Data Coordination: Reston, Va., U.S. Geological Survey, 183 p.

Kennedy, J., Goodrich, D., and Unkrich, C., 2013, Using the KINEROS2 modeling framework to evaluate the increase in storm runoff from residential development in a semi-arid environment: Journal of Hydrologic Engineering, v. 18, no. 6, p. 698-706, doi:10.1061/(ASCE)HE.1943-5584.0000655.

Moglen, G.E., and Shivers, D.E., 2006, Methods for adjusting U.S. Geological Survey rural regression peak discharges in an urban setting: U.S. Geological Survey Scientific Investigations Report 2006-5270, 65 p., available at http://pubs.usgs.gov/sir/2006/5270/.

Paretti, N.V., Kennedy, J.R., and Cohn, T.A., 2014a, Evaluation of the expected moments algorithm and a multiple low-outlier test for flood frequency analysis at streamgaging stations in Arizona: U.S. Geological Survey Scientific Investigations Report 2014-5026, 61 p., available at http://pubs.usgs.gov/sir/2014/5026/.

Paretti, N.V., Kennedy, J.R., Turney, L.A., and Veilleux, A.G., 2014b, Methods for estimating magnitude and frequency of floods in Arizona, developed with unregulated and rural peak-flow data through water year 2010: U.S. Geological Survey Scientific Investigations Report 2014-5211, 61 p., available at http://pubs.usgs.gov/sir/2014/5211/.

Pope, G.L., Rigas, P.D., and Smith, C.F., 1998, Statistical summaries of streamflow data and characteristics of drainage basins for selected streamflow-gaging stations in Arizona through water year 1996: U.S. Geological Survey WaterResources Investigations Report 98-4225, 907 p.

PRISM Climate Group, 2012, PRISM Climate Data: Oregon State University, accessed May 1, 2012, at http://prism.oregonstate.edu.

Saarinen, T.F., Baker, V., Durrenberger, R., and Maddock, T., 1984, The Tucson, Arizona, flood of October 1983: Washington, D.C., National Academy Press, 112 p.

Sauer, V.B., Thomas, W.O., Stricker, V.A., and Wilson, K.V., 1983, Flood characteristics of urban watersheds in the United States: U.S. Geological Survey Water-Supply Paper 2207, 63 p.

Southard, R.E., 2010, Estimating the magnitude and frequency of floods in urban basins in Missouri: U.S. Geological Survey Scientific Investigations Report 2010-5073, 27 p., available at http://pubs.usgs.gov/sir/2010/5073/. 
Stedinger, J.R., and Griffis, V.W., 2008, Flood frequency analysis in the United States-Time to update: Journal of Hydrologic Engineering, v. 13, p. 199-204.

U.S. Census Bureau, 2010, Population distribution and change-2000 to 2010: Census Brief C2010BR-01, 12 p. (Also available at http://www.census.gov/prod/cen2010/ briefs/c2010br-01.pdf.)
Webb, R.H., and Betancourt, J.L., 1992, Climatic variability and flood frequency of the Santa Cruz River, Pima County, Arizona: U.S. Geologic Survey Water-Supply Paper 2379, $47 \mathrm{p}$.

Yang, L., Xian, G., Klaver, J., and Deal, B., 2003, Urban landcover change detection through sub-pixel impervious surface mapping using remotely sensed data: Photogrammetric Engineering and Remote Sensing, v. 69, p. 1003-1010. 
This page intentionally left blank. 
Menlo Park Publishing Service Center, California

Manuscript approved for publication July 1, 2014

Edited by Larry Slack, Debra Grillo, and James W. Hendley II

Design and layout by Cory Hurd 
흠

돟 